\title{
Heat transfer and fluid flow analysis for turbulent flow in circular pipe with vortex generator
}

\author{
Kishor S. Rambhad ${ }^{1}$ (D) Vednath P. Kalbande ${ }^{2}$ (D) Manoj A. Kumbhalkar ${ }^{1}$ (D) $\cdot$ Vivek W. Khond $^{2}$ (D) \\ Rahul A. Jibhakate ${ }^{2} \mathbb{D}$
}

Received: 16 April 2021 / Accepted: 13 May 2021

(C) The Author(s) 2021 OPEN

\begin{abstract}
The performance of heat transfer enhancement (HTE) using modified inserts (MIs) as a vortex generator in pipe flow and fluid flow analysis using computational fluid dynamics (CFD) are evaluated in this article. The Mls are fastened to the central rod, and the circular sections of the Mls touched the circular wall of the test pipe. Heat transfer and fluid flow analyses are carried out for the various pitch to diameter ratios (P/D) and angles of the MIs. P/D ratios of 3, 4 and 6 and MIs angles of $15^{\circ}, 30^{\circ}, 45^{\circ}, 60^{\circ}$ and $90^{\circ}$ are considered for experimental analysis. CFD analysis is carried out for $P / D$ ratios of 3, 4 and 6 and Mls angles of $30^{\circ}, 45^{\circ}$ and $90^{\circ}$. Nusselt number (Nu/Nus) and friction factor (f/fs) ratios are evaluated using the same Reynolds number between 8000 and 17,000 in the experimental study. The Mls encourage the wall and core fluid to be combined thus helps in HTE. It is found that, as the P/D ratio increases, the Nu/Nus and f/fs decrease. If the distance between the Mls increases, the mixing of fluid weakens. With decreasing the P/D ratio, Nu/Nus increases. Increased fluid mixing leads to a higher coefficient of heat transfer and higher values of pressure drop. A P/D ratio of 4 and Mls angle of $45^{\circ}$ results in greater heat interaction than others. Finally, recommendations for the best P/D ratio and angles of Mls are made for improved HTE on fluid flow through a circular pipe.
\end{abstract}

Article Highlights - Modified inserts (MIs) are used inside the test pipe to check the heat transfer enhancement at various angles. Also, compared the performance with and without MIs.

Keywords Angle of modified insert · Fluid flow analysis; heat transfer enhancement · Vortex generator

$\begin{array}{ll}\text { Abbreviations } \\ \text { I } & \text { Test pipe length }(\mathrm{m}) \\ \text { Um } & \text { Mean fluid velocity }(\mathrm{m} / \mathrm{s}) \\ \Delta \mathrm{P} & \text { Pressure drop }\left(\mathrm{N} / \mathrm{m}^{2}\right) \\ \mathrm{f} & \text { Friction factor }(-) \\ \mathrm{Q} & \text { Heat transfer rate }(\mathrm{W}) \\ \mathrm{m} & \text { Mass flow rate of fluid }(\mathrm{kg} / \mathrm{s})\end{array}$

\section{Abbreviations}

Um Mean fluid velocity $(\mathrm{m} / \mathrm{s})$

$\triangle \mathrm{P}$ Pressure drop $\left(\mathrm{N} / \mathrm{m}^{2}\right)$

$\mathrm{f} \quad$ Friction factor $(-)$

$\mathrm{m}$ Mass flow rate of fluid $(\mathrm{kg} / \mathrm{s})$
- Fluid flow analysis is checked by CFD (Fluent) in Ansys software.

- Fluid flow patterns for various Mls angles and P/D ratios are compared.

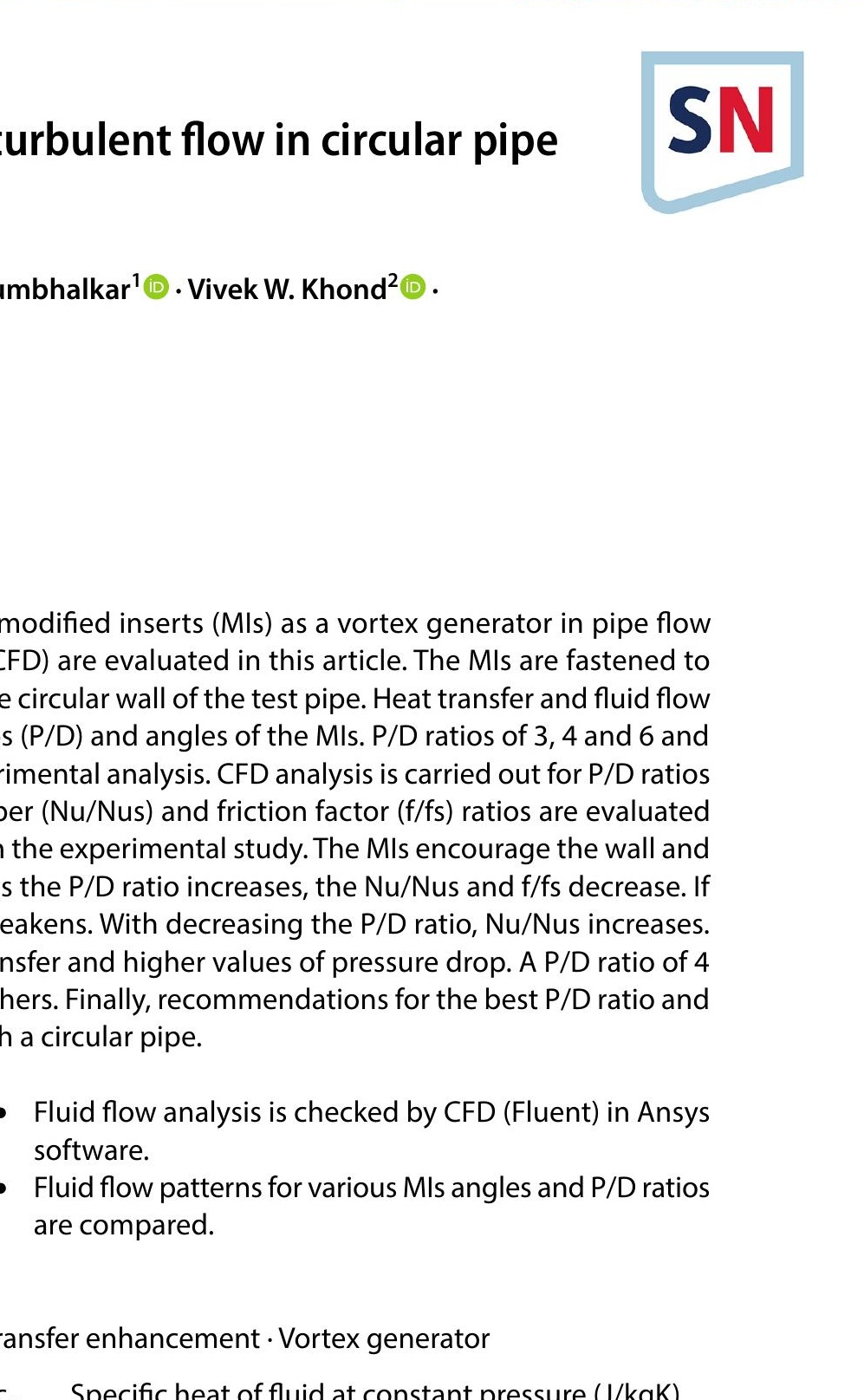

$\mathrm{C}_{\mathrm{p}} \quad$ Specific heat of fluid at constant pressure $(\mathrm{J} / \mathrm{kgK})$

$\mathrm{T} \quad$ Temperature $\left({ }^{\circ} \mathrm{C}\right)$

h Heat transfer coefficient $\left(\mathrm{W} / \mathrm{m}^{2} \mathrm{~K}\right)$

A Area of the heated region of test pipe $\left(\mathrm{m}^{2}\right)$

$\mathrm{Nu}$ Nusselt number (-)

D Inner diameter of the pipe $(\mathrm{m})$

k Thermal conductivity of the fluid $(\mathrm{W} / \mathrm{mK})$

Kishor S. Rambhad, kishorsrambhad@gmail.com; Vednath P. Kalbande, v.kalbande@raisoni.net; Manoj A. Kumbhalkar, manoj.kumbhalkar@rediffmail.com; VivekW. Khond, vivek.khond@raisoni.net; Rahul A. Jibhakate, jibhakate.rahul3@gmail.com |'JSPM Narhe Technical Campus, Pune, Maharashtra, India 411041. ${ }^{2} \mathrm{G}$ H Raisoni College of Engineering, Nagpur, Maharashtra, India 440016. 


\section{Greek symbols}

P Fluid density $(\mathrm{kg} / \mathrm{m} 3)$

$\eta \quad$ Heat transfer enhancement efficiency

\begin{tabular}{ll}
\multicolumn{2}{l}{ Subscript } \\
i & Inlet \\
o & Outlet \\
s & Smooth test pipe/test pipe without Mls
\end{tabular}

\section{Introduction}

Since the coefficient of heat transfer for gas is generally lower than liquid or two-phase flow, the output of the heat exchanger is often limited to the gas side. This improvement in heat transfer performance with reduced volume and cost of production continues to inspire research in the gas side HTE. There is a market for small-size and lightweight heat exchangers for high-performance heat transferring devices. Increasing the coefficient of heat transfer or increasing the surface area, or both can have a positive impact on capital and operating costs. HTE using inserts often results in losses in terms of pressure drop $(\Delta P)$. Circular pipe inserts are the most commonly used for HTE because they are easy to build and do not require material deformation on the inside surface of the pipe. Twisted tapes (TTs) and wire coil (WC) are the most commonly used inserts [1].

Webb et al. [2] studied rib roughness characteristics in turbulent flow through the pipe. It was observed that there is boundary layer separation and reattachment, hence repeated rib surface could be seen as a problem. At the rib, separation occurs, forming a free shear layer that re-attaches downstream from the separation point at 6-8 rib height. In the vicinity of their attachment point, a maximum heat transfer coefficient occurs. The local heat transfer coefficients for the separation flow area are greater than those of an uninterrupted boundary layer. Fiebig [3] studied five different forms of plate channel heat exchangers, showing the standard plate-fin surface for gas flow. It was observed in this analysis that the VGs surface provides greater savings in the surface area of the heat exchanger and thus in the volume of the heat exchanger. Manglik and Bergles [4] established heat transfer and $\Delta \mathrm{P}$ correlations for laminar and turbulent regimes with TTs inserts. The formation of correlation is focused on various effect. Eiamsa-ard [5] studied the heat transfer and friction characteristics in a horizontal double heat exchanger with and without TT inserts. It was observed that the best improvement for heat transfer is a single continuous tape than discontinuous tape strips as an insert. Naphon and Suwagrai [6] performed experiments using TTs, they reported that the heat transfer rate was lower than the ratio of TT pitch to higher diameter. Nag and Rao [7] reported heat transfer data for the WC insert and suggested the same correlation. For WC inserts \& TT, Wang and Sunden [8] presented a performance comparison. It was found that WC inserts provide greater overall performance than TT inserts with the same helix angle and thickness ratio also WC have much lower $\triangle \mathrm{P}$ than TT inserts. For HTE over flat surfaces, VGs namely delta wing, rectangular wing, deltawinglet pair and rectangular winglet pair were used and compared their performances by Fiebig et al. [9], delta wings have been reported to provide the greatest HTE per unit area. Yakul et al. [10] used tape in a round tube with delta-winglets-VGs on either side of the tape insert, they reported that by increasing winglet height, the Nusselt number increases slightly, but the friction factor also increases sharply by increasing winglet height and ring sector insert angle. Akhavan-Behabadi et al. [11] studied forced convective evaporation characteristics of $\Delta \mathrm{P}$ in heat transfer in horizontal tubes with WC inserts. The helical WC with different coil pitches of $0.5,0.8,1$ and $1.3 \mathrm{~cm}$ and different wire diameters of $0.05,0.07,0.1$ and $0.15 \mathrm{~cm}$ were developed and the test pipe was used at full length. For the plain tube and each inserted tube, several trials were performed for several fluid velocities and heat fluxes. The analysis of the data collected showed that the WC inserts increases the heat transfer coefficient, but it leads to higher $\Delta \mathrm{P}$. Rambhad et al. [12, 13] studied the HTE performance using aluminium WC in evacuated glass tube used as an absorber in parabolic trough solar collector, researchers also compared the heat transfer performance through test pipe with and without WC. Huang et al. [14] improve core flow heat transfer by a porous medium insert in a tube. Naphon and Suchana [15] examined HTE and $\Delta \mathrm{P}$ in the horizontal concentric tube with twisted wire brush inserts. The analysis of HTEs with TT inserts located separately from the tube wall was carried out by Bas and Ozceyhan [16]. Salam et al. [17] used rectangular-cut TTs as an insert to study HTE in the pipe. Eiamsa-Ard and Kiatkittipong [18] used $\mathrm{TiO}_{2} /$ water nanofluid along with multiple TT inserts for HTE in the pipe. In tubes based on genetic algorithm and CFD, Zheng et al. [19] studied HTE using porous insert configurations. Haskins and El-Genk [20] studied CFD analysis and correlation of concentration and helically shell-side $\Delta \mathrm{P}$. Meinicke et al. [21] investigated single-phase hydrodynamics and conjugate heat transfer in solid sponges using scale-resolved CFD modelling. Sharifi et al. [22] used CFD analysis to investigate the effects of helical WC inserts on heat transfer and $\Delta \mathrm{P}$ in a double-pipe heat exchanger. Tusar et al. [23] performed CFD analysis of HTE and fluid flow analysis. A CFD analysis was carried out by Pandey et al. [24] for 
HTE and flow characteristics of a circular tube heat exchanger using a Y-shaped insert. Dang and Wang [25] studied convective HTE mechanisms in a circular tube with a twin coil type insert. Wijayanta et al. [26] and Chokphoemphun et al. [27] investigated HTE of internal flow using punched delta winglet vortex generators (PDWVGs), PDWVGs provide higher heat transfer and pressure loss than plain tube was observed. The hydro-thermal efficiency of rectangular winglet vortex generators (RWVGs) was tested numerically and experimentally by Liu et al. [28], the results indicate that the RWVGs can agitate the cold fluid from the central flow area to the tube wall, thus improving the mixing of hot and cold fluids. Awais and Bhuiyan [29] Summarized the $\mathrm{HTE}$ and $\triangle \mathrm{P}$ using Delta winglet vortex generators provide better thermal output than rectangular type, found Optimum angle of attack of $30^{\circ}$ and $45^{\circ}$ for HTE. Gallegos and Sharma [30] provides a review on the use of flexible plates i.e., flags as vortex generators inside a channel for HTE technology. Mahanthesh et al. [31] investigates the heat transfer properties of a nanofluid flowing over a rotating disc in the presence of a magnetic field and a convective boundary condition. Rasool and Shafiq [32] used a nonlinearly settled stretching sheet/surface, line up the MHD, heat sink/source, and convective boundary conditions in chemically reactive radiative Powell-Eyring nanofluid flow through Darcy tube. The effects of binary chemical reaction, thermal radiation, and Soret-Dufour effects on a constant incompressible Darcy-Forchheimer flow of nanofluids were studied by Rasool et al. [33].

The use of heat exchanging devices in the various application has been increased. Hence to increase the heat transfer rate is a crucial issue from a heat-saving point of view. The heat-saving challenge encourages the researcher to find an alternative to heat transfer technology. By studying the previous work, motivation for the fabrication of modified insert to enhance the heat transfer rate is developed.

The objective of the present work is to investigate HTE and fluid flow characteristics in the circular test pipe using MIs as a VGs. The use of WC, TTs, etc. as VGs for HTE is popular, but very little literature is available on the use of circumferential VGs in a circular tube. The attempt here is to get high HTE with less $\triangle \mathrm{P}$. Specially designed insert assemblies have been used for this purpose and results for the Reynolds number between 8000 and 17,000 are obtained.

In this paper, an experimental study is performed using Mls. Gap analysis is obtained from the exhaustive literature review which encouraged in designing Mls. Comparison of present experimental study is carried out with twisted tape insert for the validation. CFD analysis is also performed to check the flow behaviours in the test pipe with and without MIs. Finally, a conclusion is presented for heat transfer enhancement, pressure drop and fluid flow analysis.

\section{Experimental setup}

An experimental testing facility is built to measure the coefficient of heat transfer in a smooth and Mls-fitted pipe. As shown in Fig. 1, the Schematic of the testing facility and photograph of the test set are shown in Fig. 2.

Blower drives fluid into the test section (the air is taken as a working fluid in this study). In the test section, a venturimeter mounted before the test section measures mass flow rate and fluid velocity. To measure $\Delta P$ across the venturimeter, a $\mathrm{U}$-tube manometer containing water as a manometric fluid is connected to the two pressure taps attached at the entrance and throat of the venturimeter. The $\Delta \mathrm{P}$ in the test pipe is also measured by $\mathrm{U}$-tube manometer connected across the inlet and outlet
Fig. 1 Schematic diagram of the experimental setup

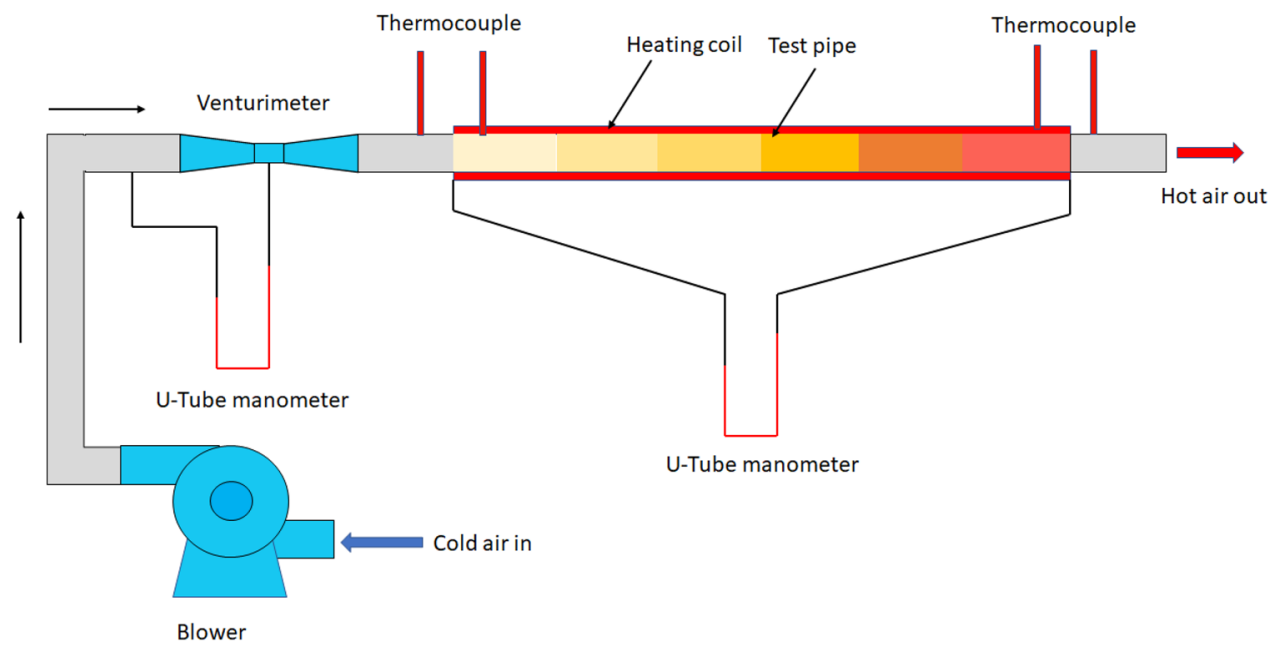

SN Applied Sciences A SPRINGER NATURE journal 


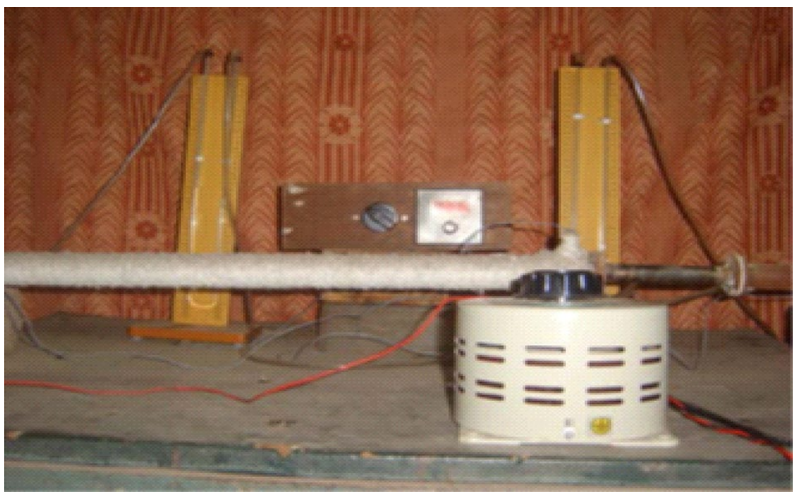

Fig. 2 Photograph of the experimental setup

of the test pipe. The test section is made of stainless steel pipe, has a wall thickness of $0.5 \mathrm{~mm}$ with $1000 \mathrm{~mm}$ length (I) and $25 \mathrm{~mm}$ inner diameter (D). The test pipe is wounded by a nichrome wire for induction heating. The heat loss to the surroundings is prevented by insulation provided over nichrome wire. The regulated power is provided to the nichrome wire via dimmer-stat, which supplies the test pipe with uniform heat flux. The fluid inlet and outlet temperatures were measured by precalibrated thermocouples.

The geometry of typical MIs is shown in Fig. 3a, b shows pipe fitted with Mls and Fig. $3 c$ shows the CAD model of Mls fitted insert. Figure 4 shows the photograph of Mls fastened on a mild steel rod.

The circular geometry of the test pips has been occupied by the MIs. Mls are made from aluminium sheets $0.4 \mathrm{~mm}$ thick. The Mls are cut into the circular section of $25 \mathrm{~mm}$ diameter. At a definite axial pitch, and a definite angle from the axis of the test pipe, in the flow direction, Mls are fastened to a $3 \mathrm{~mm}$ mild steel rod. In the test section length (I) with the help of mean fluid velocity $(\mathrm{Um})$, fluid density $(\rho)$ and pressure drop $(\Delta P)$, the friction factor (f) is determined (as shown in Eq. 1) [17].

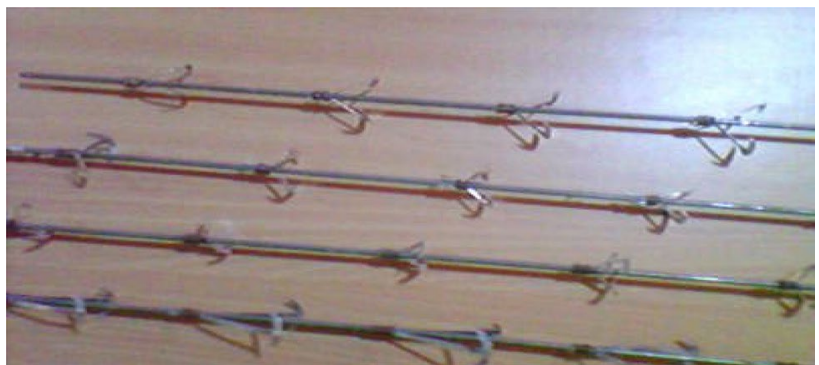

Fig. 4 Photograph of modified insert fitted on the central rod

$f=\frac{\Delta p}{\rho\left(\frac{1}{D}\right)\left(\frac{U m^{2}}{2}\right)}$

The friction factor is based on actual experimental conditions.

Heat carried $(\mathrm{Q})$ by fluid flows through the test pipe is determined in terms of the mass flow rate of fluid $(m)$, the specific heat of fluid at constant pressure $\left(c_{p}\right)$, an inlet temperature of the fluid $\left(T_{i}\right)$ and outlet temperature of the fluid $\left(T_{0}\right)$ by Eq. 2 [17]:

$Q=m c_{p}\left(T_{o}-T_{i}\right)$

Average heat transfer coefficient (h) based on net heat transfer rate $(\mathrm{Q})$ and area of heated region of the test pipe (A) is calculated by Eq. 3 [17]:

$h=\frac{Q}{\mathrm{~A}\left(T_{o}-T_{i}\right)}$

The Nusselt number ( $\mathrm{Nu}$ ) for fully developed flow through the test pipe with Mis is calculated in terms of heat transfer coefficient $(h)$, an inner diameter of the pipe (D) and thermal conductivity of the fluid (k) by Eq. 4 [17]:

$N u=\frac{h D}{k}$

For various Reynolds number, the pitch to diameter ratio and Mls angle, the experimental and CFD analysis
Fig. 3 a Modified insert b Pipe fitted with Modified insert c CAD model of Mls fitted test pipe

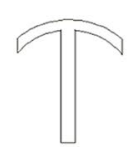

(a)

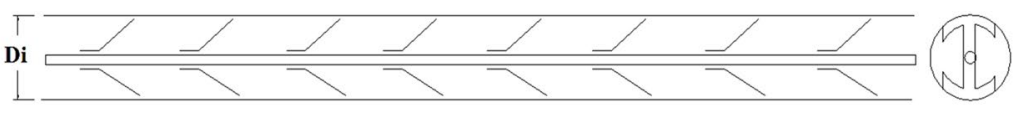

(b)

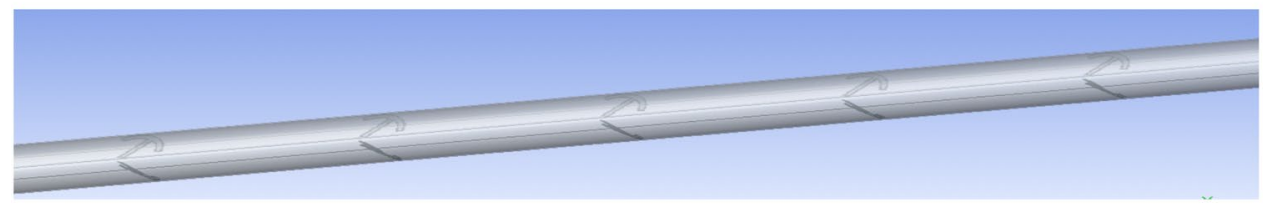

(c) 
was carried out. The improvement of the heat transfer enhancement efficiency ( $\eta$ ) is reported in the form of the ratio of the Nusselt number (Nu/Nus) in Eq. 5 [17].

$\eta=\frac{N u}{N u s}$

\section{Result and discussion}

\subsection{Experimental analysis of heat transfer enhancement}

The test pipe diameter was taken as the hydraulic diameter for the fluid flow. Experimentation is performed for a fully developed flow. An experimental investigation is conducted for the various P/D ratio, various Mls angle and the various fluid flow rate. For Reynolds numbers between 8000 and 17,000 (turbulent flow), the results obtained are discussed in this paper. The results of this study are presented as the $\mathrm{Nu} / \mathrm{Nus}$ and $\mathrm{f} / \mathrm{fs}$ to influence the Mls performance parameter based on the same Reynolds number. $\mathrm{Nu}$ is the experimental value of the Nusselt number in the presence of the Mls. Nus is the experimental value of the Nusselt number of the test pipe without MIs for the same Reynolds number. $\mathrm{f} / \mathrm{fs}$ is the friction factor ratio of the experimental value of the friction factor of pipe without and with Mls for the same Reynolds number. Figures 5 and 6 shows the variation of $\mathrm{Nu} / \mathrm{Nus}$ and $\mathrm{f} / \mathrm{fs}$ respectively for $P / D=3$. Figures 7 and 8 shows the variation of Nu/Nus and $f / f s$ respectively for $P / D=4$. Figures 9 and 10 shows the variation of $\mathrm{Nu} / \mathrm{Nus}$ and $\mathrm{f} / \mathrm{fs}$ respectively for $\mathrm{P} / \mathrm{D}=6$.

\subsection{Validation of experimental results}

To validate the present experimental results, the experimental results of test pipe fitted with Mls are compared with an experimental study carried out for twisted tape inserts by Salam et al. [17].
Fig. 5 Variation of $\mathrm{Nu} / \mathrm{Nus}$ with Reynolds Number at $P / D=3$
Fig. 6 Variation of $f / f s$ with Reynolds Number at $P / D=3$
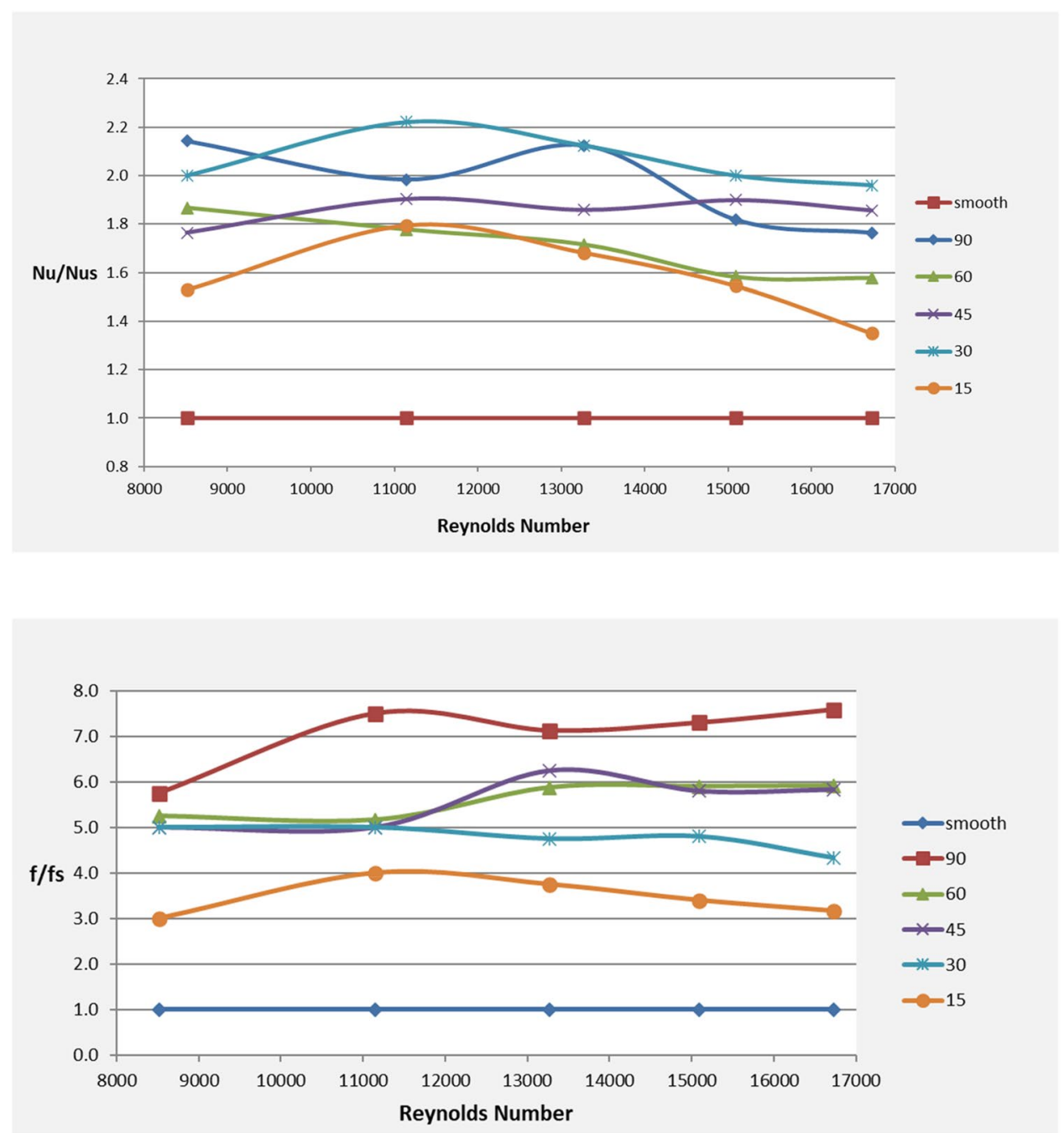
Fig. 7 Variation of $\mathrm{Nu} / \mathrm{Nus}$ with Reynolds Number at $P / D=4$

Fig. 8 Variation of $f / f s$ with Reynolds Number at $\mathrm{P} / \mathrm{D}=4$

Fig. 9 Variation of $\mathrm{Nu} / \mathrm{Nus}$ with Reynolds Number at $P / D=6$
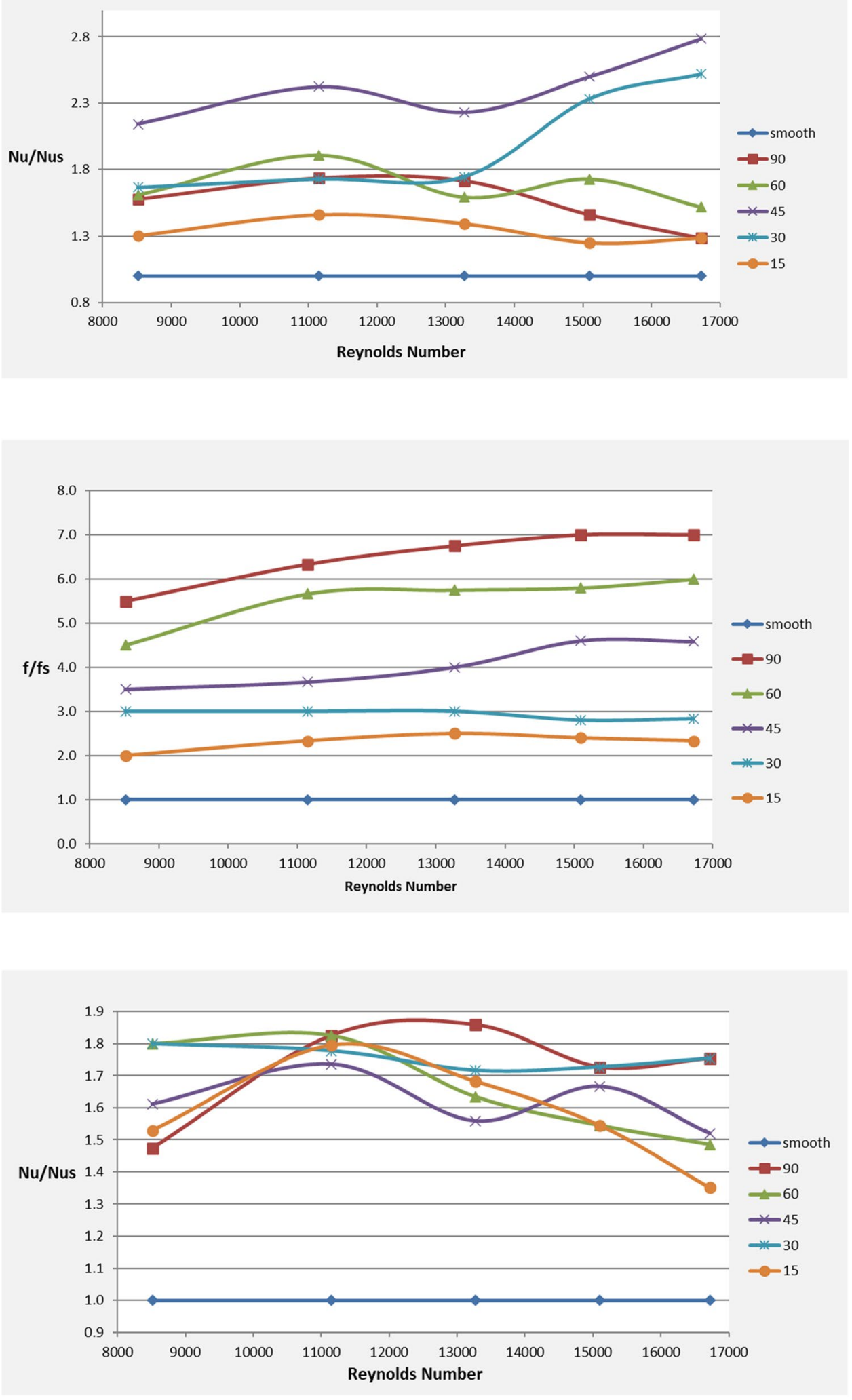
Fig. 10 Variation of $f / f s$ with Reynolds Number at $P / D=6$

Fig. 11 Variation of $\mathrm{Nu} / \mathrm{Nus}$ with Reynolds Number at $\mathrm{P} / \mathrm{D}=3$ for Mls and Twisted tape

Fig. 12 Variation of Nu/Nus with Reynolds Number at $P / D=4$ for MIs and Twisted tape
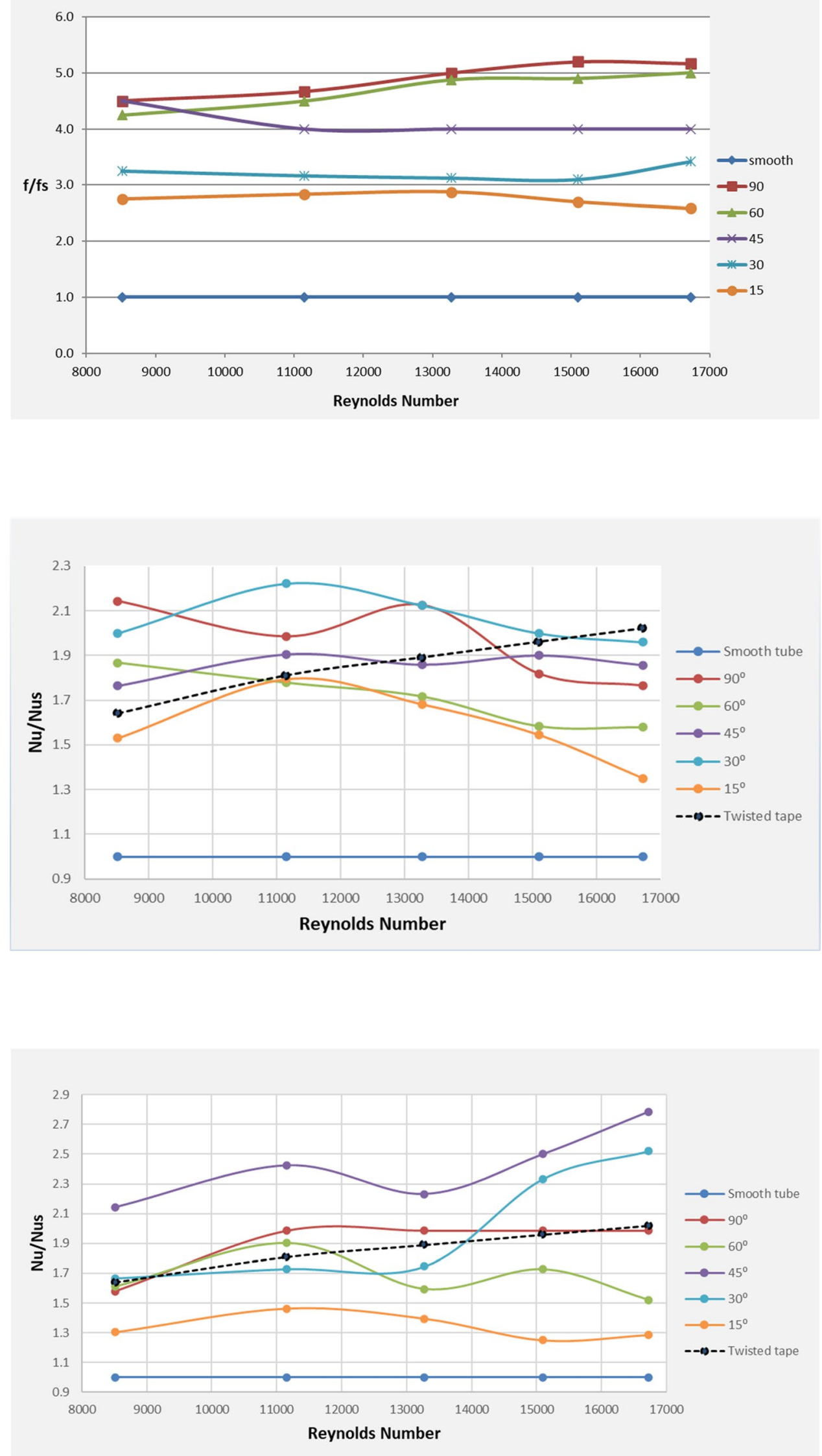

SN Applied Sciences

A SPRINGER NATURE journa 
Figures $11,12,13$ shows the comparison of heat transfer enhancement efficiency (Nu/Nus) for Mls and Twisted tape used by Salam et al. [17]. For twisted tape as an insert, it is observed that the $\mathrm{Nu} / \mathrm{Nus}$ ratio increases as the Reynolds number increase hence twisted tape is a good alternative as an insert for a higher Reynolds Number. For MIs as an insert, it is observed that the trend of Nu/Nus ratio is different for different MIs angles and P/D ratios. Since the best result is obtained for Mls angle of $45^{\circ}$ and $P / D$ ratio of 4 , a comparison of heat transfer enhancement using twisted tape is made with this. From Fig. 14 it is observed that, for Mls angle of $45^{\circ}$ and P/D ratio of 4 , as the Reynolds number increases Nu/Nus ratio also increase and it is much higher than twisted tape inserts for the same Reynolds number. Table 1 shows the percent improvement in heat transfer enhancement efficiency (Nu/Nus) of Mls for Mls angle of $45^{\circ}$ and $P / D$ ratio of 4 over the twisted tape. Hence present paper recommends the use of Mls with an angle of $45^{\circ}$ and
Fig. 13 Variation of $\mathrm{Nu} / \mathrm{Nus}$ with Reynolds Number at $\mathrm{P} / \mathrm{D}=6$ for Mls and Twisted tape
Fig. 14 Comparison of heat transfer enhancement efficiency (Nu/Nus) between Mls (Mls angle $=45^{\circ}$ and $\mathrm{P} / \mathrm{D}=4$ ) and Twisted tape
Table 1 Percent improvement of heat transfer enhancement efficiency (Nu/Nus) of Mls (Mls angle $=45^{\circ}$ and $\left.P / D=4\right)$ over the Twisted tape
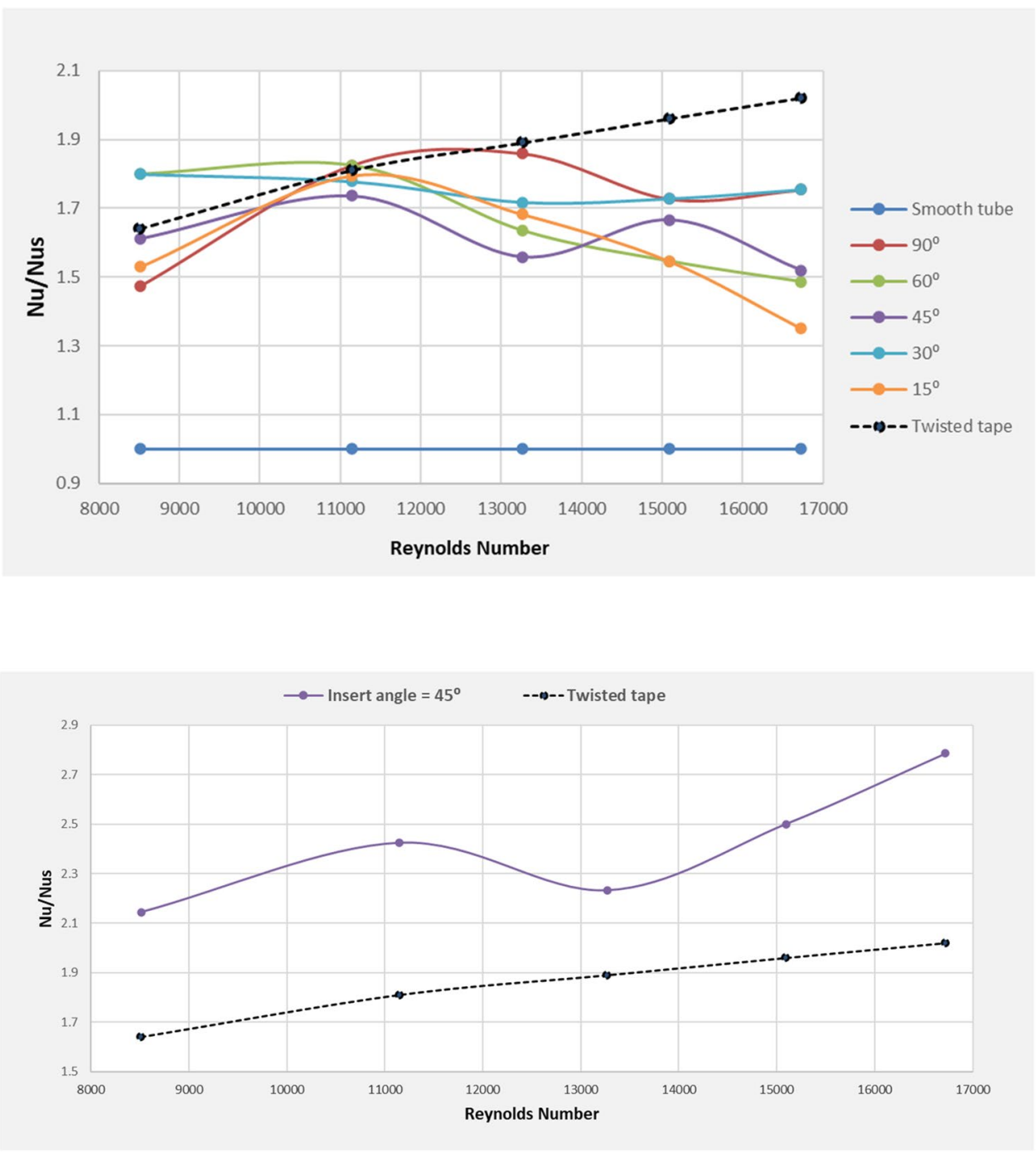

\begin{tabular}{lllll}
\hline Sr. no. & Reynolds Number & Nu/Nus (MIs) & $\begin{array}{l}\text { Nu/Nus } \\
\text { (Twisted tape) }\end{array}$ & $\begin{array}{l}\text { Percent improvement in Nu/Nus } \\
\text { of Mls over the twisted tape (\%) }\end{array}$ \\
\hline 1 & 8514 & 2.14 & 1.64 & 30.66 \\
2 & 11148 & 2.42 & 1.81 & 33.93 \\
3 & 13269 & 2.23 & 1.89 & 18.05 \\
4 & 15095 & 2.50 & 1.96 & 27.55 \\
5 & 16722 & 2.78 & 2.02 & 37.90 \\
\hline
\end{tabular}


$\mathrm{P} / \mathrm{D}$ ratio of 4 for better heat transfer enhancement and low $\Delta \mathrm{P}$ in a circular pipe at all ranges of Reynolds number.

\subsection{Fluid flow analysis using CFD}

The main difficulty in the experimental investigation is to check the fluid flow behaviour through a test pipe. Hence CFD analysis is used to check fluid flow behaviour only through the test pipe. CFD analysis is an alternative to various methods available to check fluid behaviour and it is readily available in various software. Hence, to study the behaviour of fluid flow in the test pipe with and without MIs, CFD (Fluent) tool is used in the Ansys software. Ansys 2019 R3 version is utilized for fluid flow analysis. Fluid flow analysis using CFD is performed for test pipe with and without Mls. Mls is considered for P/D ratios of 3, 4 and 6 and angles of Mls of $90^{\circ}, 45^{\circ}$ and $30^{\circ}$. The average values of experimental analysis for velocities, temperatures and pressures are taken for CFD analysis.

Table 2. shows the results of CFD analysis for fluid flow and heat transfer. Table 3. shows the fluid flow pattern through the pipe with and without Mls in the form of streamlines.

From Tables 2 and 3 it is observed that temperature increases from inlet to outlet gradually. Wall fluid absorbs heat from the test pipe first, then the core fluid absorbs heat from its adjacent hot layer of fluid. Cold fluid enters the test pipe, as it progresses in the test pipe cold fluid gets heated.

The velocity of the fluid in the smooth pipe is uniform throughout near the wall of the pipe but the velocity of fluid flowing through the core of the pipe increase first then decrease. When the fluid flowing through the pipe fitted with Mls, the velocity of the fluid is very less (sometimes reaches zero $\mathrm{m} / \mathrm{s}$ ) in the line of Mls and higher in another region.

The pressure of the fluid at the entry of the pipe is very high, but as the fluid progresses in the pipe, pressure decreases and reaches the atmospheric pressure at the outlet in the smooth pipe. But in the pipe fitted with Mls, very high $\Delta \mathrm{P}$ was observed (sometimes fluid reaches to vacuum in the line MIs).

Flow pattern (streamlines) observed straight for the smooth pipe but as the Mls angle decreases from 90 to $30^{\circ}$ streamlines showed a behaviour change. For Mls angles of $90^{\circ}$ and $45^{\circ}$ streamlines are almost the same, in these angles of Mls streamlines are straight in the vacant region and streamlines deviate in the Mls region in the test pipe. Streamlines are highly disturbed for Mls angle of $30^{\circ}$, streamlines move in the circular pattern while moving in the test pipe.
On the flow pattern i.e., streamlines, there is a great influence of $P / D$ ratio and Mls angle. At Mls angle of $30^{\circ}$, for $P / D$ of 3 and 4 , flow is highly disturbed and swirling action observed but for $P / D$ ratio of 6 , flow is uniform and streamlines are seemed to be straight which implies increased $P / D$ ratio recommendation for uniformed flow.

\section{Conclusion}

It is observed that, as the P/D ratio of the Mls increases, the $\mathrm{Nu} / \mathrm{Nus}$ and $\mathrm{f} / \mathrm{fs}$ decreases. The Mls encourages the wall and core fluid to be mixed. As the distance between the Mls increases, the mixing of fluid weakens. With decreasing the P/D ratio, Nu/Nus increases. Increased fluid mixing contributes to a higher coefficient of heat transfer and higher values of $\triangle P . A P / D=4$ results in better heat interaction than others.

Next, a fixed Reynolds number has been taken and the Mls angle is varied. As the Mls angle decreases from 90 to $15^{\circ}$, the Nu/Nus and f/fs decreases. Nu/Nus and f/ $f s$ increase with increasing Mls angle. With an increase in Mls angle, the Nu/Nus values indicate a small increase. The greater Mls angle implies a longer mixing zone between the core and the wall fluid, enhancing the coefficient of heat transfer. The cross-stream mixing also induces a greater $\Delta \mathrm{P}$. To fasten the Mls with the central rod, the projection of the Mls is necessary. This protrusion adds to the flow resistance, thus increasing the value of $f / f s$. This, on the other hand, increases the mixing of fluids and facilitates increased heat transfer. The best results have been obtained for optimum Mls angle values $=45^{\circ}$ and $P / D=4$.

Present experimental work is compared with twisted tape insert for the validation and authenticity of the experiment. It is observed that, Mls shown greater HTE than the twisted tape insert in the same range of Reynolds number.

Fluid flow analysis is also carried out in this work using the CFD tool. Using the CFD tool heat transfer, velocity, $\triangle \mathrm{P}$ patterns and fluid flow behaviour are studied. Fluid flow analysis is explained in detail in the result and discussion section and related images are displayed in Tables 2 and 3. Matching results are found in HTE for experimental and CFD studies.

From the future research point of view, it is very important to consider a higher Mls angle (Maximum $90^{\circ}$ ) for HTE. In this work higher $\triangle \mathrm{P}$ and disturbed flow pattern observed for Mls angle $30^{\circ}$ and it would increase for Mls angle $15^{\circ}$ further which is certainly not recommended for the future research point of view. 
Table 2 Results of CFD analysis for fluid flow and heat transfer

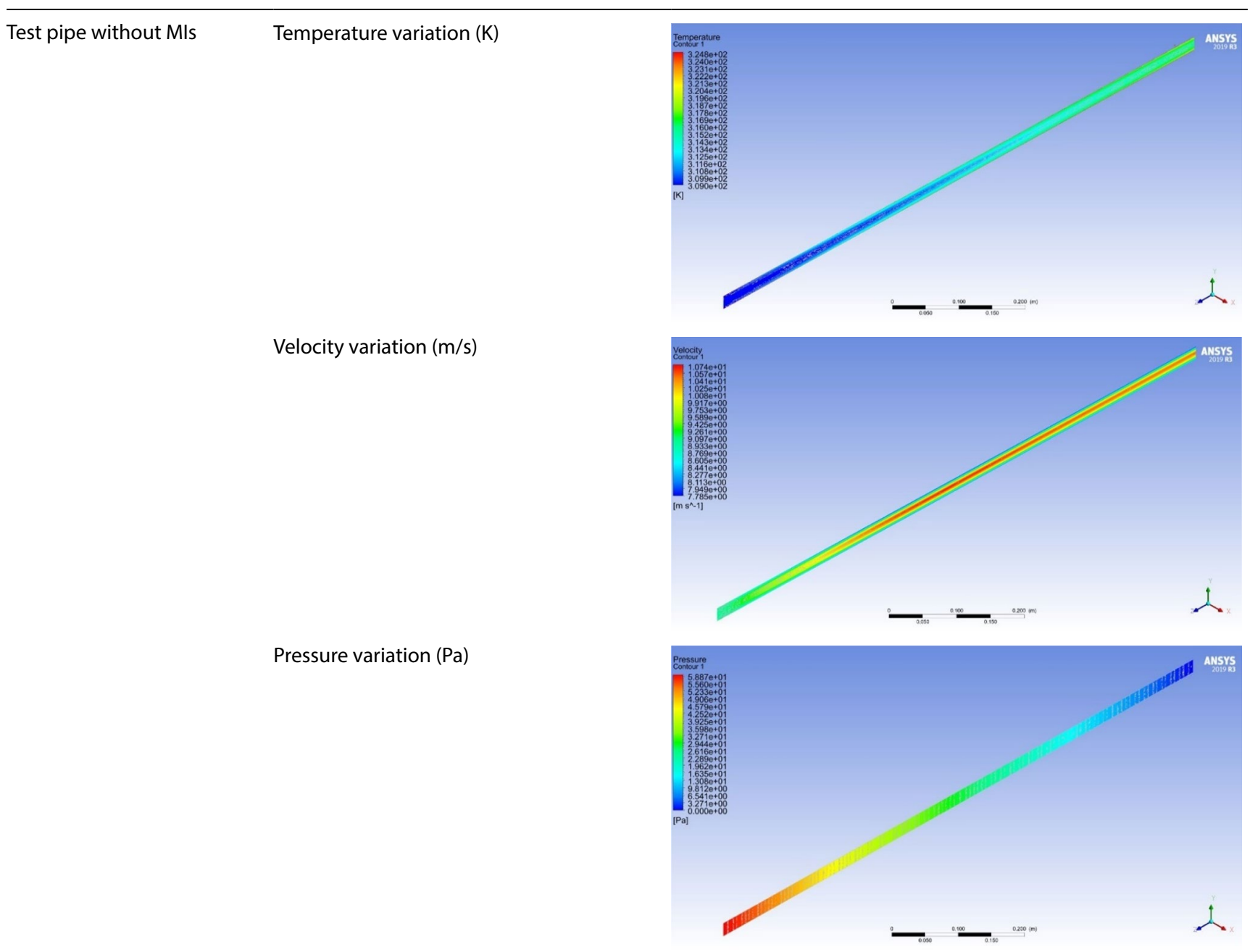

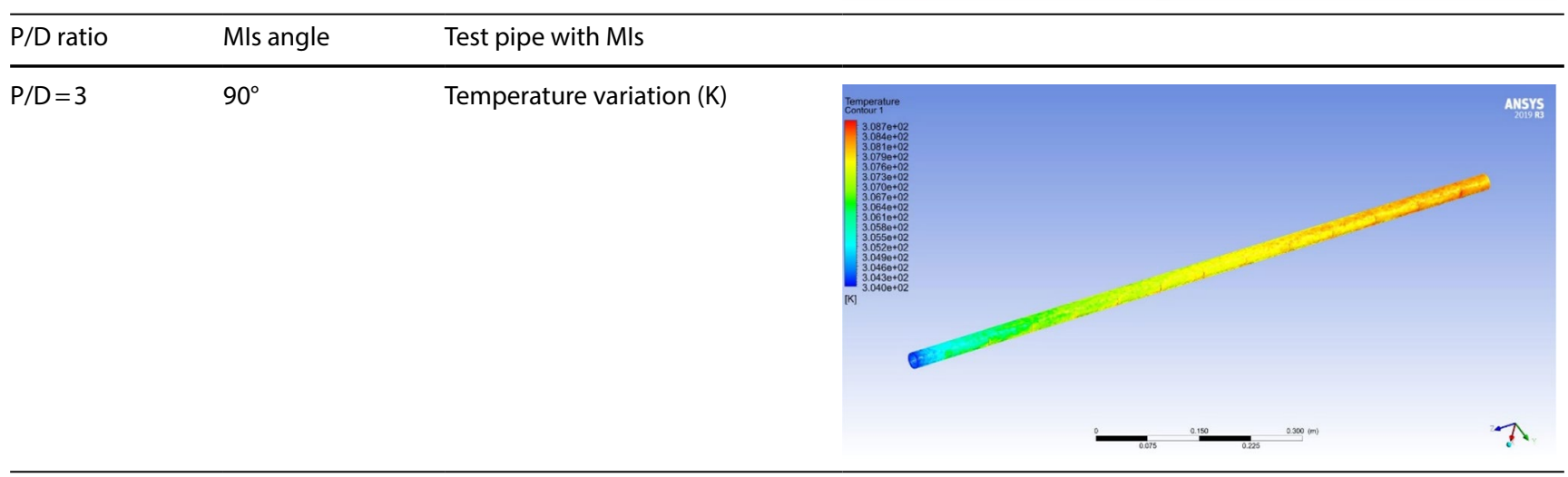


Table 2 (continued)

\begin{tabular}{lll}
\hline P/D ratio & Mls angle & Test pipe with Mls \\
\hline & Velocity variation $(\mathrm{m} / \mathrm{s})$
\end{tabular}

Velocity variation $(\mathrm{m} / \mathrm{s})$

Pressure variation $(\mathrm{Pa})$

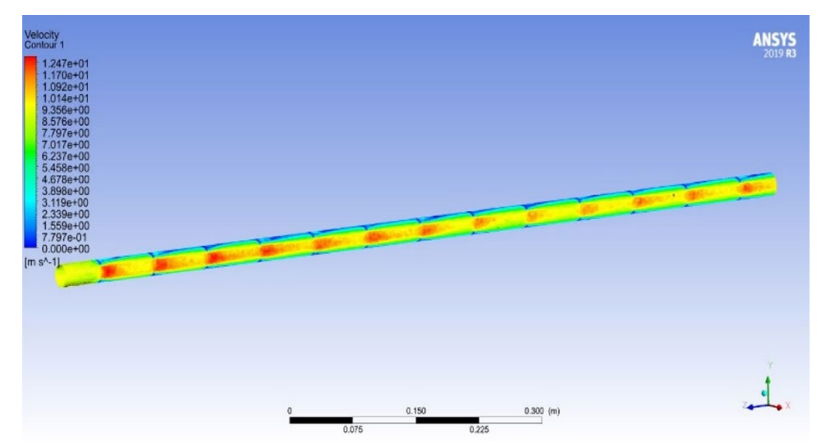

\section{Pressure variation (Pa)}
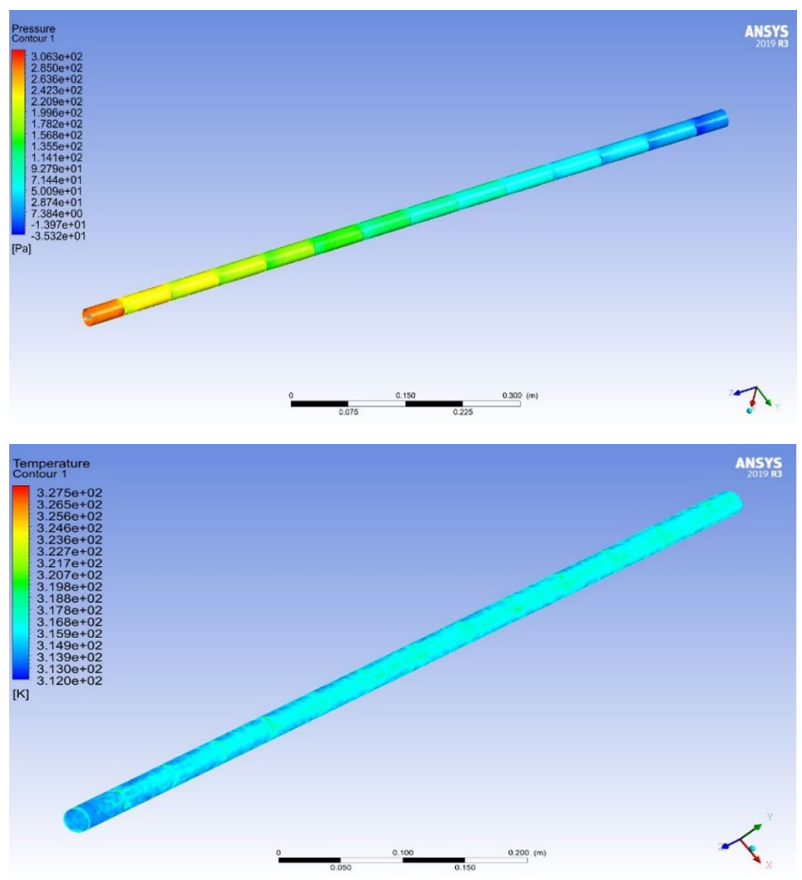

Velocity variation $(\mathrm{m} / \mathrm{s})$

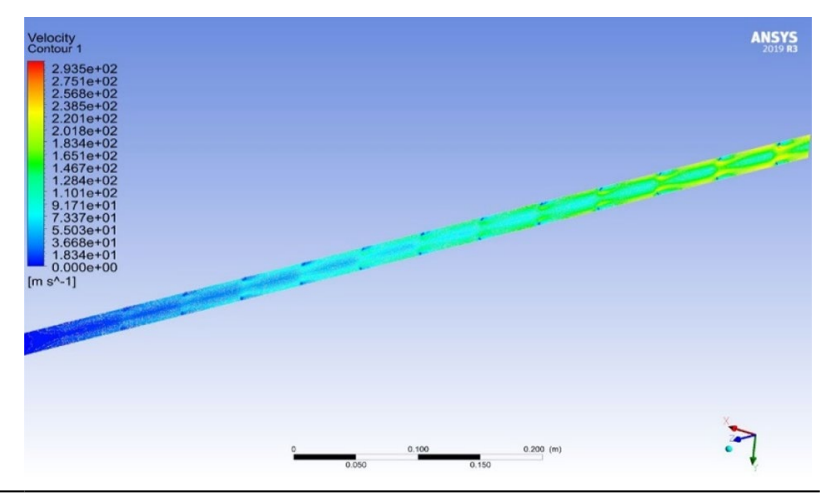


Table 2 (continued)

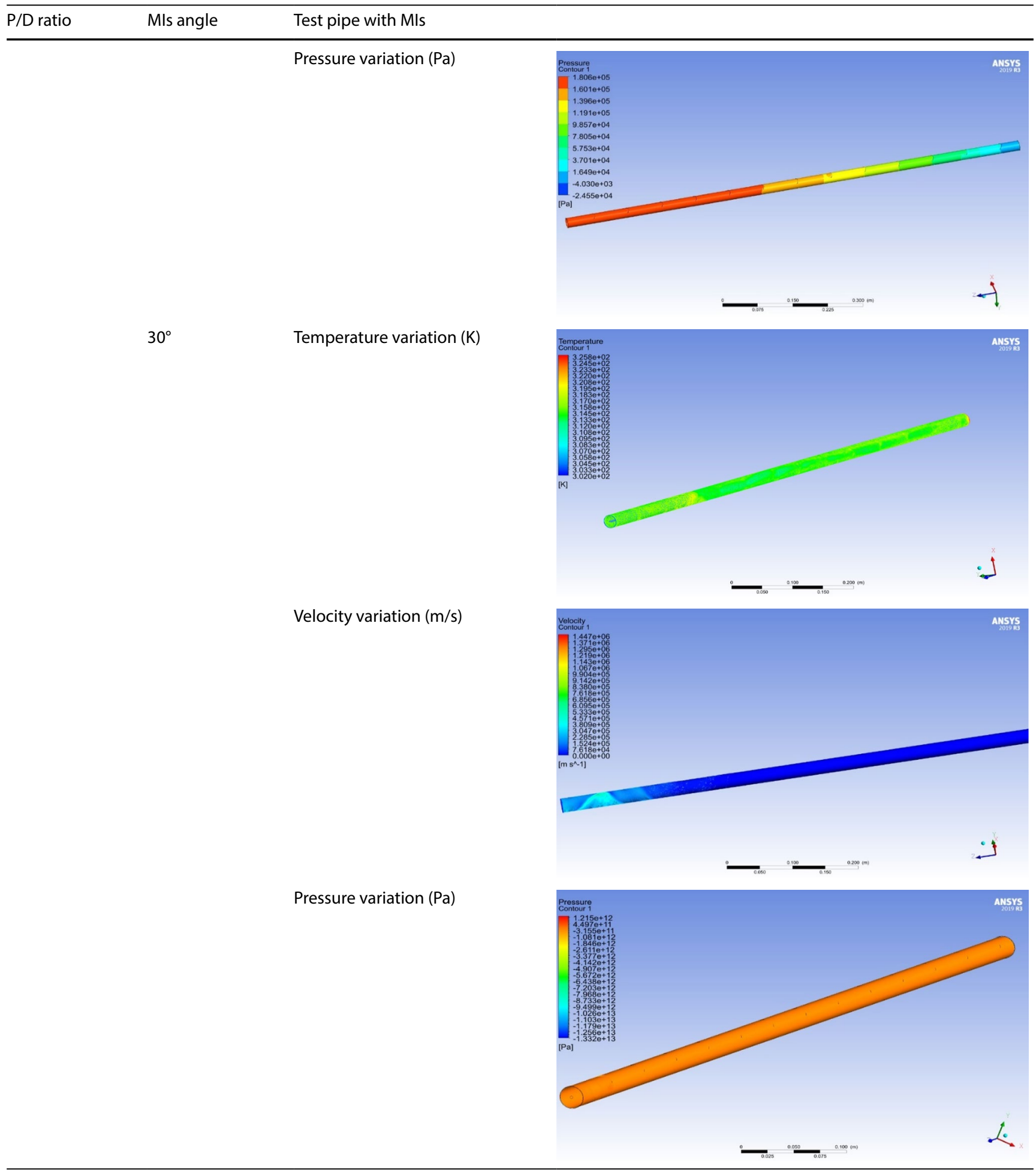


Table 2 (continued)

\begin{tabular}{lll}
\hline $\mathrm{P} / \mathrm{D}$ ratio & Mls angle & Test pipe with Mls \\
\hline $\mathrm{P} / \mathrm{D}=4$ & $90^{\circ}$ & Temperature variation $(\mathrm{K})$
\end{tabular}

Velocity variation $(\mathrm{m} / \mathrm{s})$

Pressure variation $(\mathrm{Pa})$
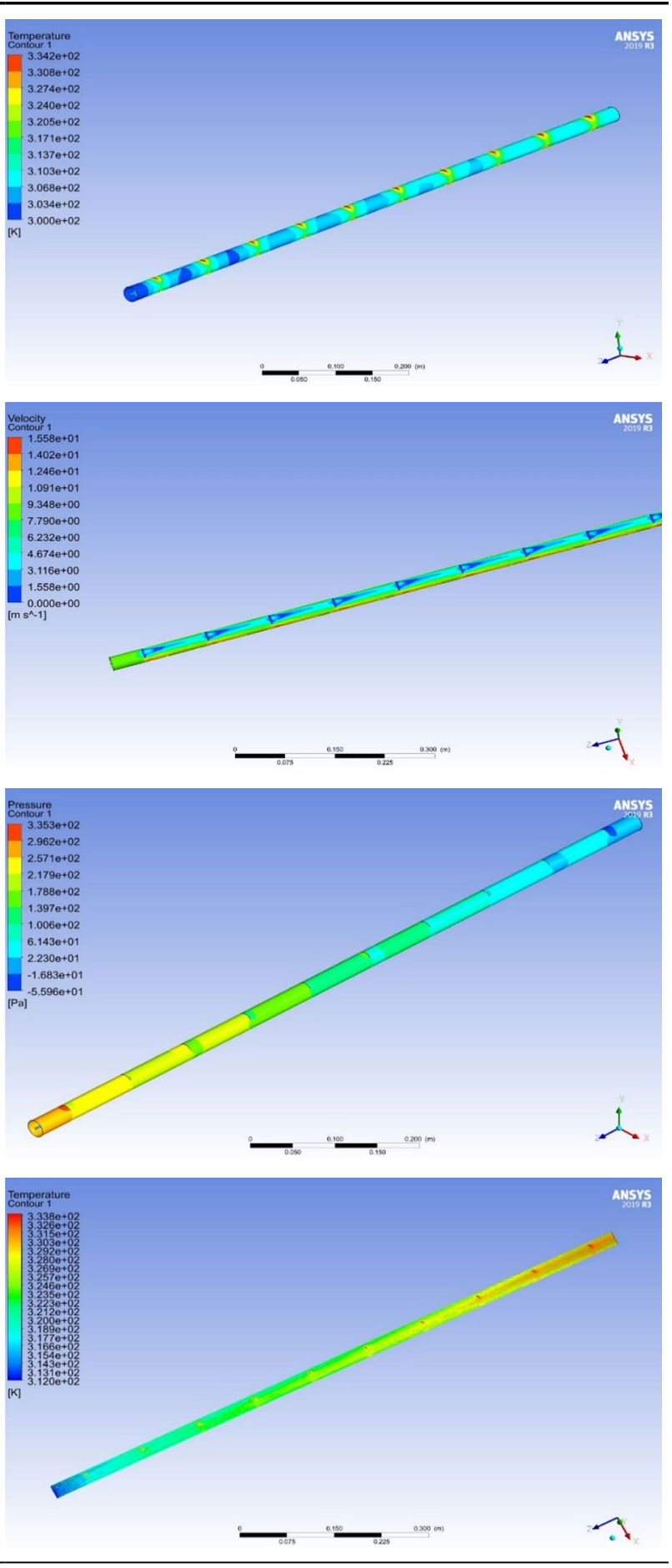
Table 2 (continued)

\begin{tabular}{lll}
\hline P/D ratio & Mls angle & Test pipe with Mls \\
\hline & Velocity variation $(\mathrm{m} / \mathrm{s})$
\end{tabular}

Velocity variation $(\mathrm{m} / \mathrm{s})$

Pressure variation $(\mathrm{Pa})$
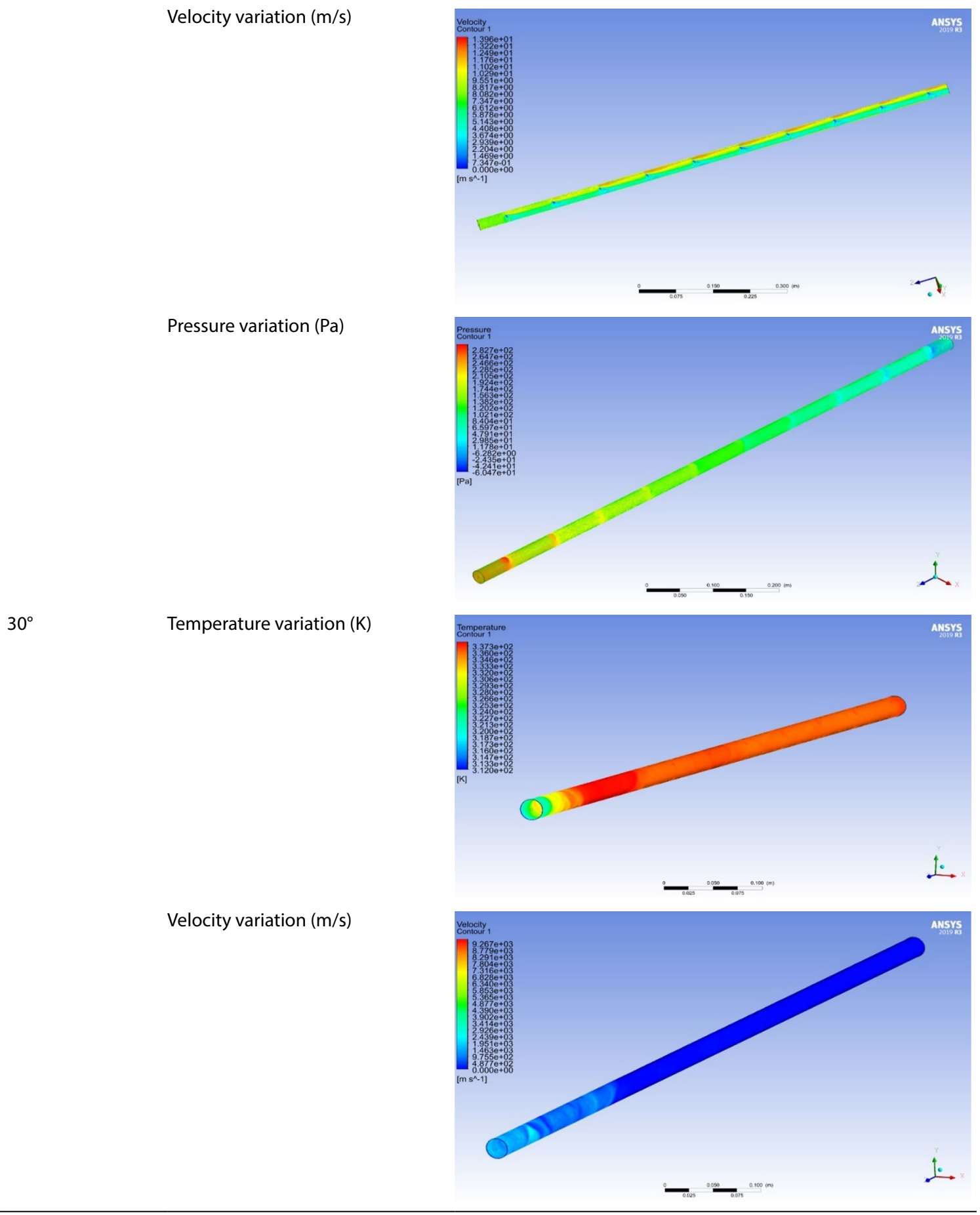
Table 2 (continued)

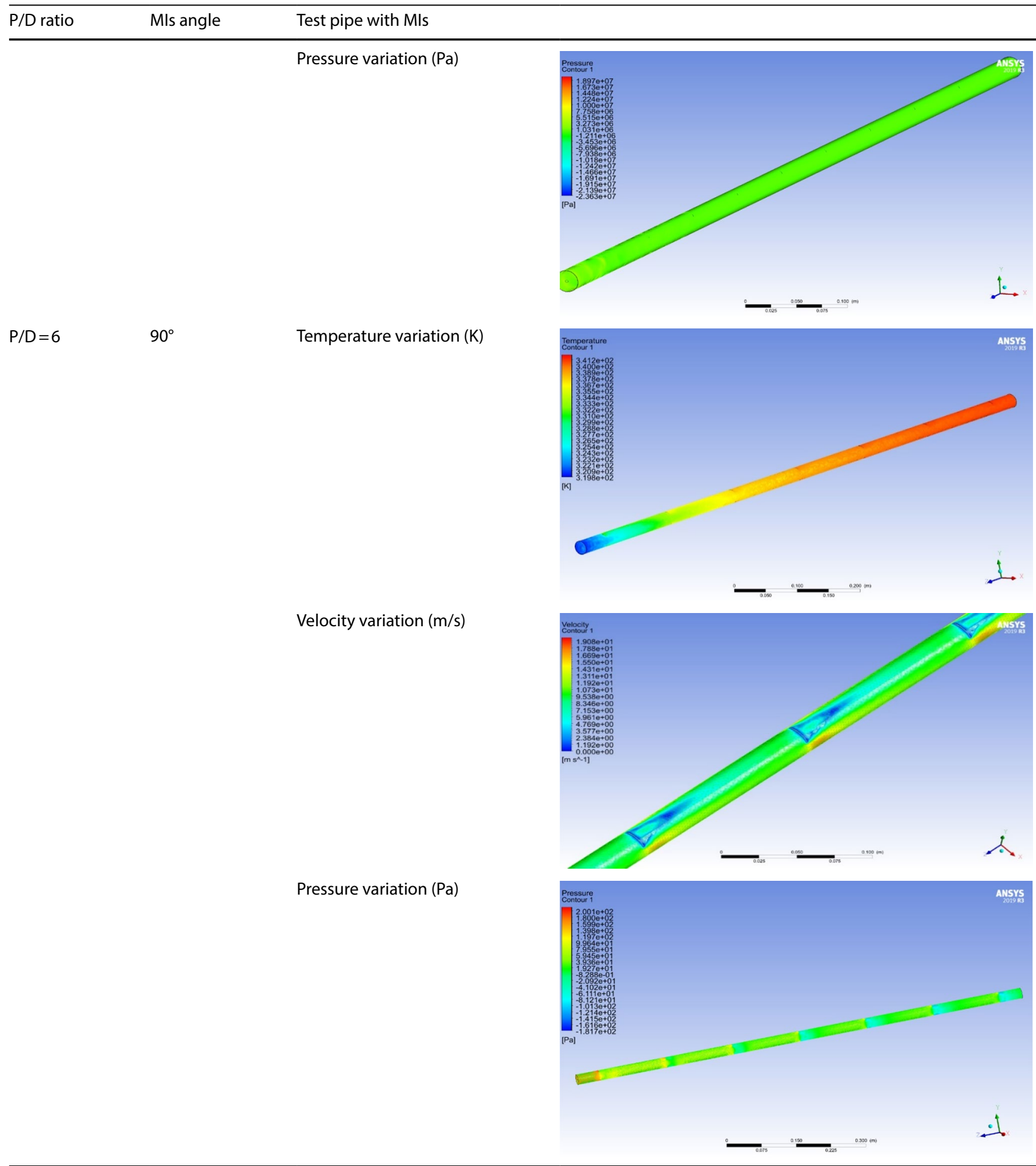


Table 2 (continued)

\begin{tabular}{lll}
\hline P/D ratio & Mls angle & Test pipe with Mls \\
\hline $45^{\circ}$ & Temperature variation $(\mathrm{K})$
\end{tabular}

Velocity variation $(\mathrm{m} / \mathrm{s})$
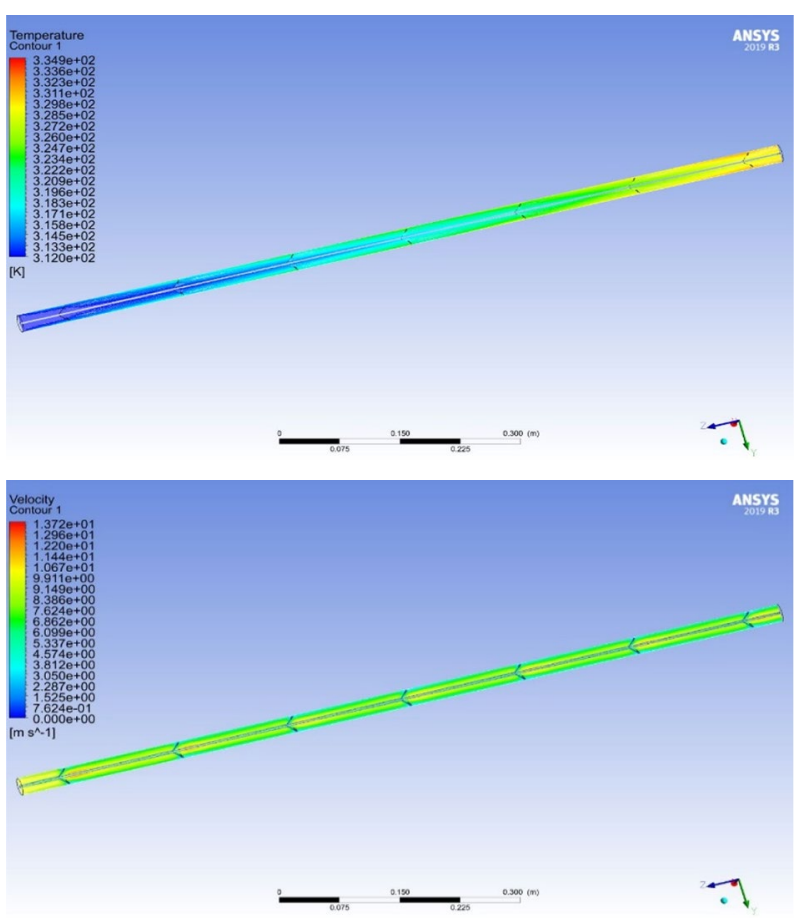

Pressure variation $(\mathrm{Pa})$
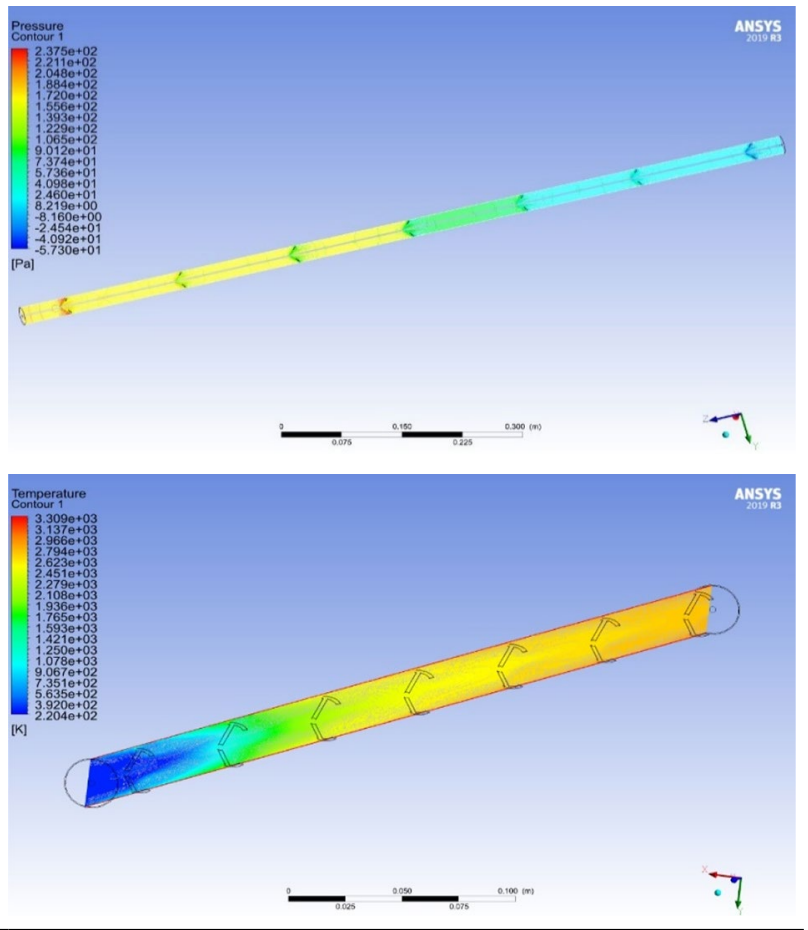
Table 2 (continued)

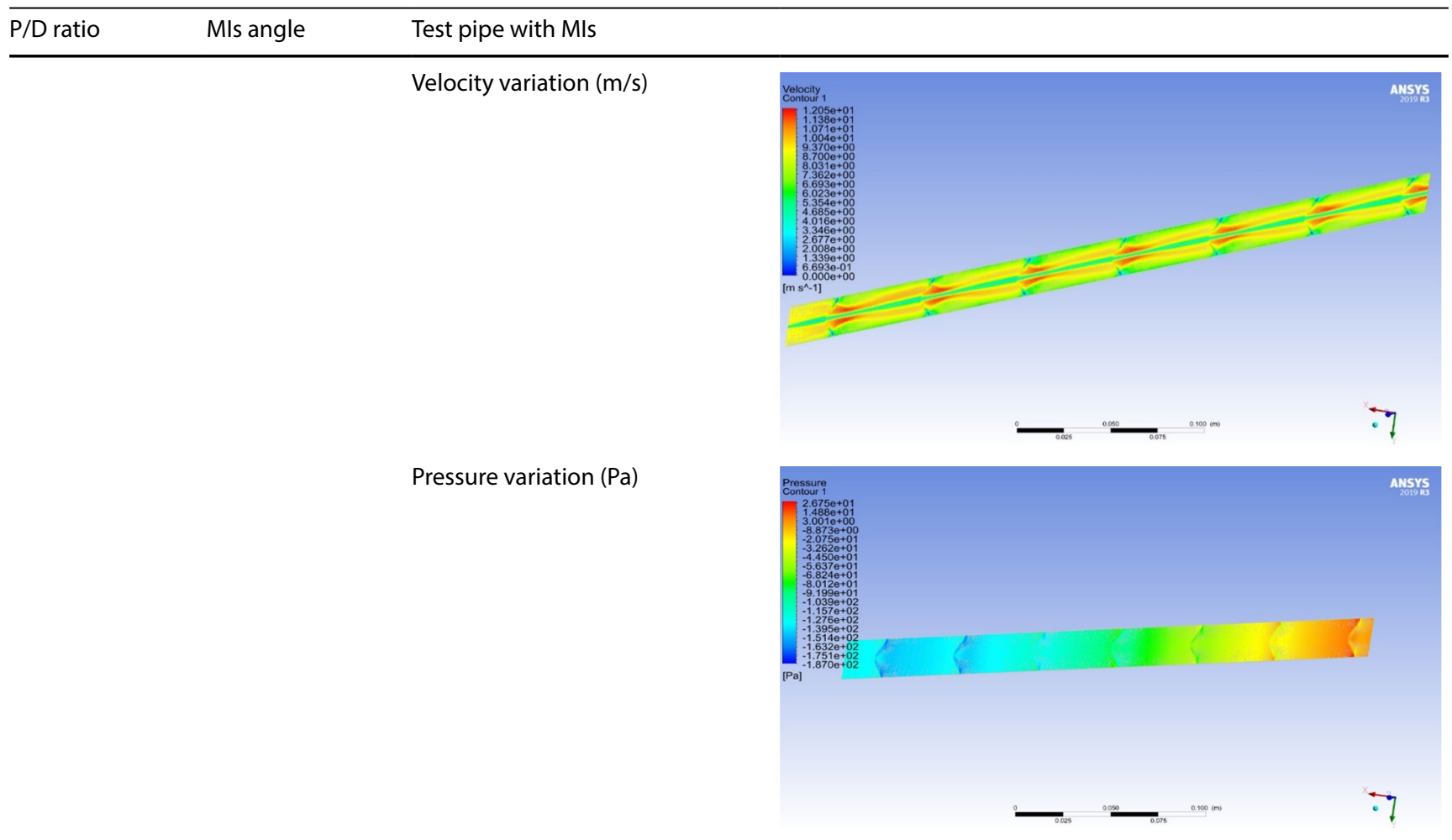


Table 3 The fluid flow pattern through the pipe with and without Mls in the form of streamlines

P/D ratio Mls angle

Test pipe without Mls

Pipe without MIs

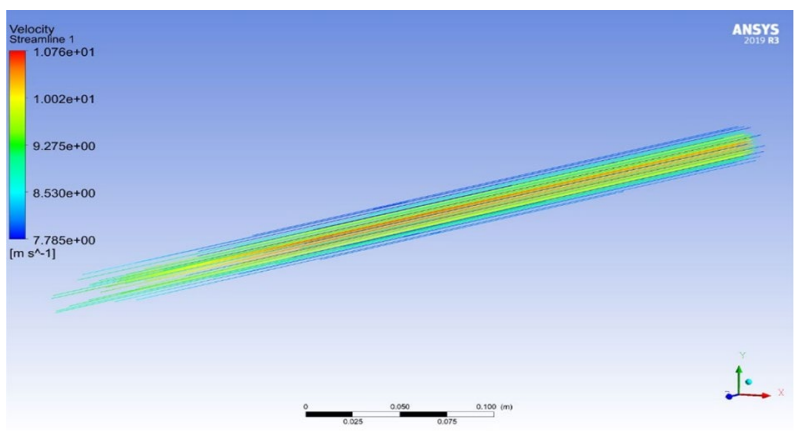

Test pipe with Mls

$P / D=3$

$90^{\circ}$

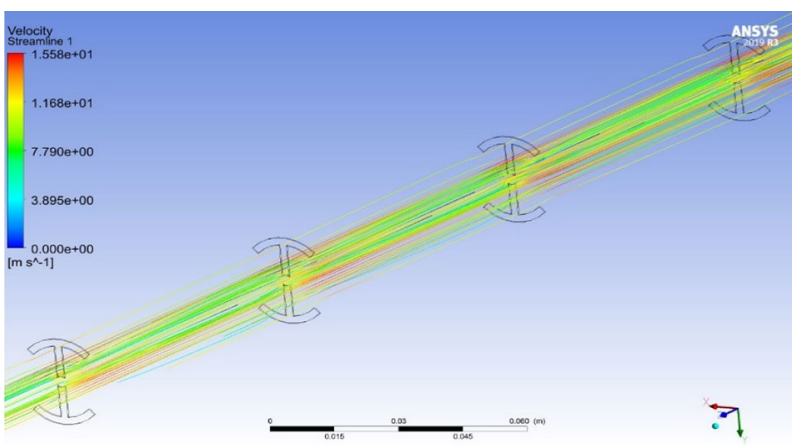

$45^{\circ}$

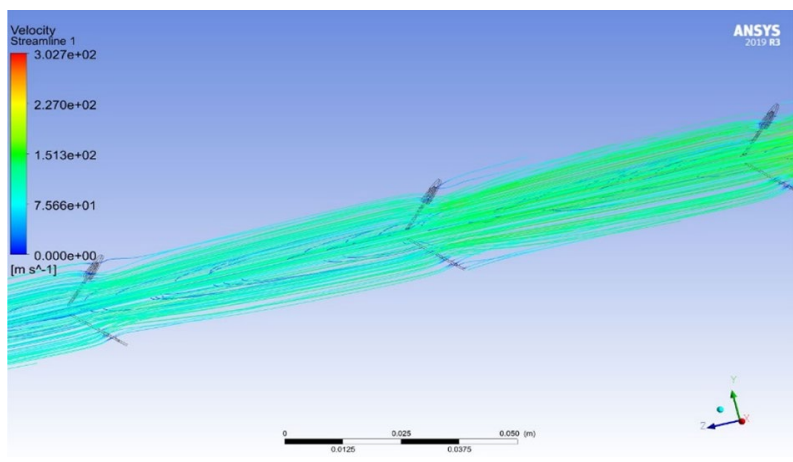

$30^{\circ}$

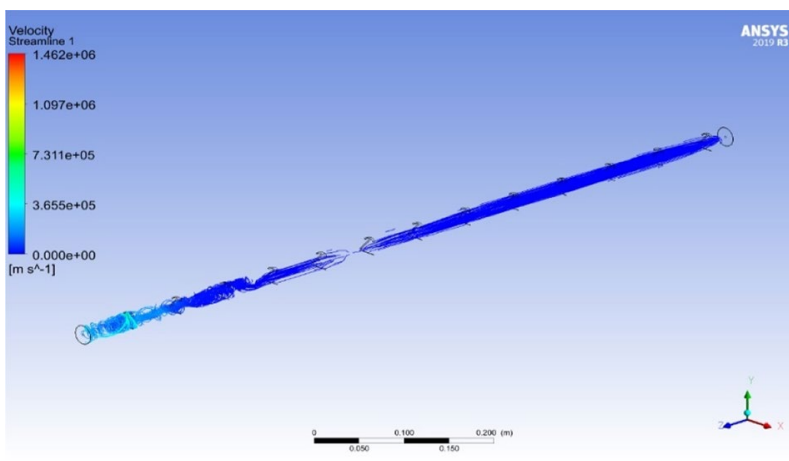


Table 3 (continued)

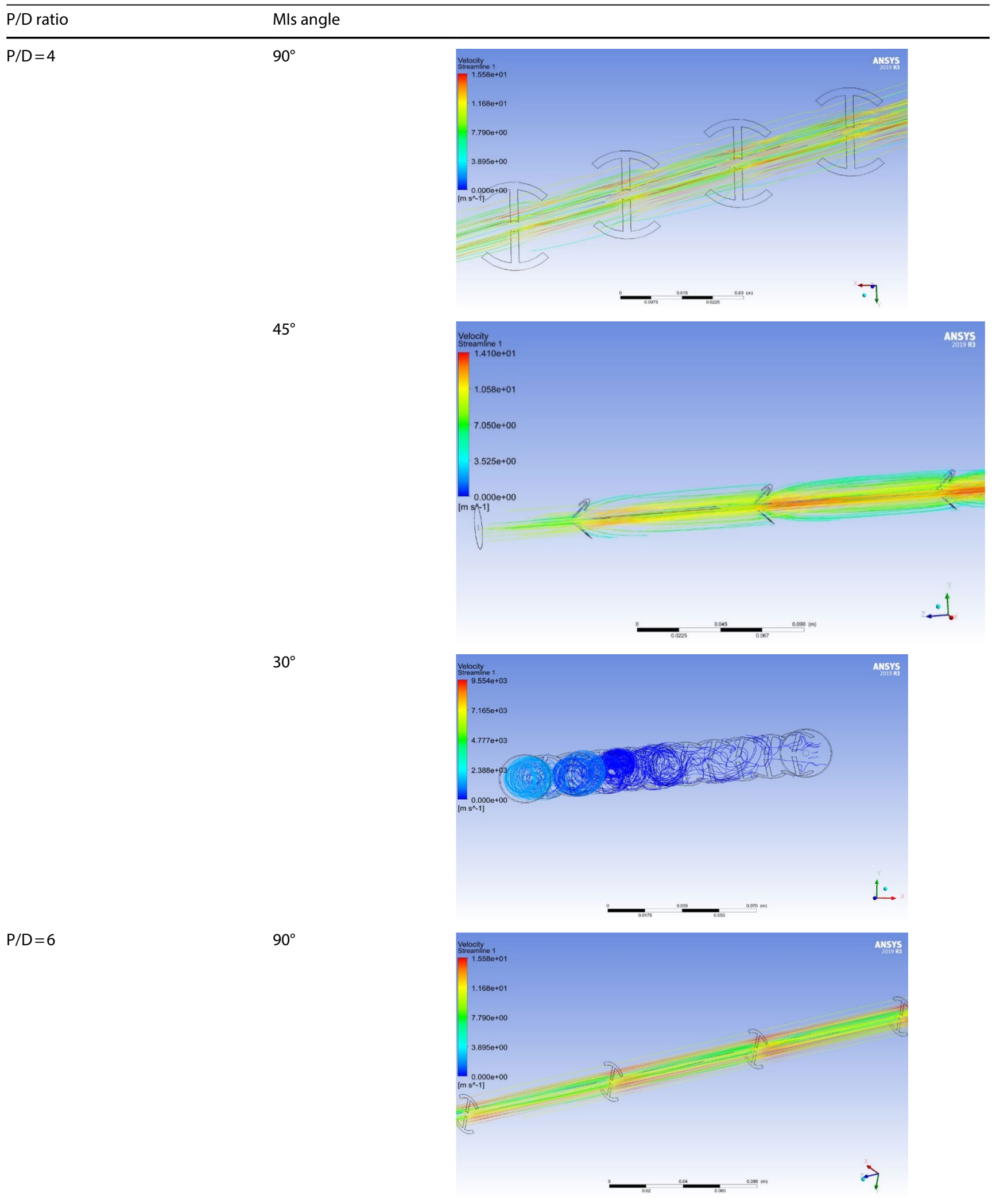


Table 3 (continued)

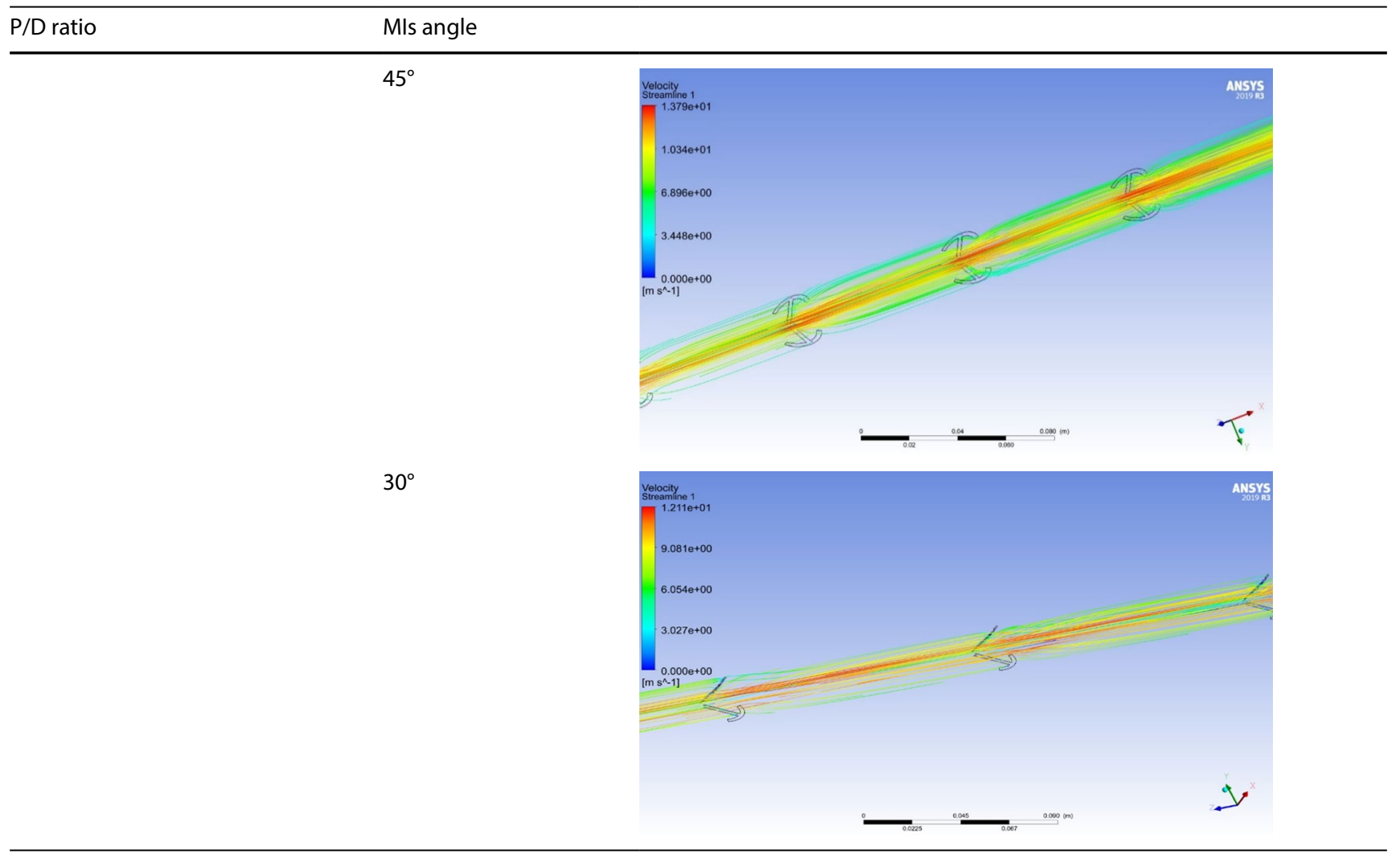

Acknowledgements We would like to mention that, this work is not funded by any external or internal agency. We are deeply grateful to JSPM Narhe Technical Campus, Pune for providing a platform for CFD analysis, Visvesvaraya National Institute of Technology for providing a platform for Experimentation and G. H. Raisoni College of Engineering, Nagpur for providing a platform for Plagiarism checking.

Funding This research work has been carried out without any funding from internal as well as external agencies.

Availability of data and material This manuscript has no associated data or the data will not be deposited.

\section{Declarations}

Conflict of interest On behalf of all authors, the corresponding author states that there is no conflict of interest.

Open Access This article is licensed under a Creative Commons Attribution 4.0 International License, which permits use, sharing, adaptation, distribution and reproduction in any medium or format, as long as you give appropriate credit to the original author(s) and the source, provide a link to the Creative Commons licence, and indicate if changes were made. The images or other third party material in this article are included in the article's Creative Commons licence, unless indicated otherwise in a credit line to the material. If material is not included in the article's Creative Commons licence and your intended use is not permitted by statutory regulation or exceeds the permitted use, you will need to obtain permission directly from the copyright holder. To view a copy of this licence, visit http://creativecommons. org/licenses/by/4.0/.

\section{References}

1. Mousa MH, Miljkovic N, Nawaz K (2021) Review of heat transfer enhancement techniques for single phase flows. Renew Sustain Energy Rev 137:1 10566. https://doi.org/10.1016/j.rser.2020. 110566

2. Webb RL, Eckert ERG, Goldstein RJ (1971) Heat transfer and friction in tubes with repeated-rib roughness. Int J Heat Mass Transf 14:601-617. https://doi.org/10.1016/0017-9310(71)90009-3

3. Fiebig M (1995) Embedded vortices in internal flow: heat transfer and pressure loss enhancement. Int J Heat Fluid Flow 16:376-388

4. Manglik RM, Bergles AE (1993) Heat transfer and pressure drop correlations for twisted-tape inserts in isothermal tubes: part II-Transition and turbulent flows. J Heat Transfer 115:890-896. https://doi.org/10.1115/1.2911384

5. Eiamsa-ard S, Thianpong C, Promvonge P (2006) Experimental investigation of heat transfer and flow friction in a circular tube fitted with regularly spaced twisted tape elements. Int Commun Heat Mass Transf 33:1225-1233. https://doi.org/10.1016/j.ichea tmasstransfer.2006.08.002

6. Naphon P, Suwagrai J (2007) Effect of curvature ratios on the heat transfer and flow developments in the horizontal spirally coiled tubes. Int J Heat Mass Transf 50:444-451. https://doi.org/ 10.1016/j.ijheatmasstransfer.2006.08.002 
7. Nag S, Rao MR (1987) Forced convection heat transfer in smooth tubes roughened by helically coiled ribbons. Int J Heat Mass Transf 30:1541-1544. https://doi.org/10.1016/0017-9310(87) 90186-4

8. Wang L, Sundén B (2002) Performance comparison of some tube inserts. Int Commun Heat Mass Transf 29:45-56. https://doi.org/ 10.1016/S0735-1933(01)00323-2

9. Fiebig M, Kallweit $P$, Mitra N, Tiggelbeck S (1991) Heat transfer enhancement and drag by longitudinal vortex generators in channel flow. Exp Therm Fluid Sci 4:103-114. https://doi.org/ 10.1016/0894-1777(91)90024-L

10. Yakut K, Sahin B, Celik C et al (2005) Effects of tapes with doublesided delta-winglets on heat and vortex characteristics. Appl Energy 80:77-95. https://doi.org/10.1016/j.apenergy.2004.03. 003

11. Akhavan-Behabadi MA, Mohseni SG, Najafi $\mathrm{H}$, Ramazanzadeh $\mathrm{H}$ (2009) Heat transfer and pressure drop characteristics of forced convective evaporation in horizontal tubes with coiled wire inserts. Int Commun Heat Mass Transf 36:1089-1095. https:// doi.org/10.1016/j.icheatmasstransfer.2009.07.009

12. Rambhad KS, Walke PV (2018) Regeneration of composite desiccant dehumidifier by parabolic trough solar collector : an experimental investigation. Mater Today Proc 5:24358-24366. https:// doi.org/10.1016/j.matpr.2018.10.231

13. Rambhad KS, Walke PV (2017) An experimental investigation of solar assisted air heating for solid desiccant regeneration using parabolic trough solar concentrator. Int J Anal Exp Finite Elem Anal 4:45-47

14. Huang ZF, Nakayama A, Yang K et al (2010) Enhancing heat transfer in the core flow by using porous medium insert in a tube. Int J Heat Mass Transf 53:1164-1174. https://doi.org/10. 1016/j.ijheatmasstransfer.2009.10.038

15. Naphon P, Suchana T (2011) Heat transfer enhancement and pressure drop of the horizontal concentric tube with twisted wires brush inserts. Int Commun Heat Mass Transf 38:236-241. https://doi.org/10.1016/j.icheatmasstransfer.2010.11.018

16. Bas H, Ozceyhan V (2012) Heat transfer enhancement in a tube with twisted tape inserts placed separately from the tube wall. Exp Therm Fluid Sci 41:51-58. https://doi.org/10.1016/j.expth ermflusci.2012.03.008

17. Salam B, Biswas S, Saha S, Bhuiya MMK (2013) Heat transfer enhancement in a tube using rectangular-cut twisted tape insert. Procedia Eng 56:96-103. https://doi.org/10.1016/j.proeng.2013.03.094

18. Eiamsa-Ard S, Kiatkittipong K (2014) Heat transfer enhancement by multiple twisted tape inserts and TiO 2/water nanofluid. Appl Therm Eng 70:896-924. https://doi.org/10.1016/j.appltherma leng.2014.05.062

19. Zheng ZJ, Li MJ, He YL (2015) Optimization of porous insert configurations for heat transfer enhancement in tubes based on genetic algorithm and CFD. Int J Heat Mass Transf 87:376-379. https://doi.org/10.1016/j.ijheatmasstransfer.2015.04.016

20. Haskins DA, El-Genk MS (2016) CFD analyses and correlation of pressure losses on the shell-side of concentric, helically-coiled tubes heat exchangers. Nucl Eng Des 305:531-546. https://doi. org/10.1016/j.nucengdes.2016.05.014

21. Meinicke S, Wetzel T, Dietrich B (2017) Scale-resolved CFD modelling of single-phase hydrodynamics and conjugate heat transfer in solid sponges. Int J Heat Mass Transf 108:1207-1219. https://doi.org/10.1016/j.ijheatmasstransfer.2016.12.052

22. Sharifi K, Sabeti M, Rafiei M et al (2018) Computational fluid dynamics (CFD) technique to study the effects of helical wire inserts on heat transfer and pressure drop in a double pipe heat exchanger. Appl Therm Eng 128:898-910. https://doi.org/10. 1016/j.applthermaleng.2017.08.146

23. Tusar M, Ahmed K, Bhuiya M et al (2019) CFD study of heat transfer enhancement and fluid flow characteristics of laminar flow through tube with helical screw tape insert. Energy Proced 160:699-706

24. Pandey L, Prajapati H, Singh S (2020) CFD study for enhancement of heat transfer and flow characteristics of circular tube heat exchanger using Y-shaped insert. Mater Today Proc. https:// doi.org/10.1016/j.matpr.2020.10.890

25. Dang W, Wang LB (2021) Convective heat transfer enhancement mechanisms in circular tube inserted with a type of twined coil. Int J Heat Mass Transf 169:120960. https://doi.org/10.1016/j. ijheatmasstransfer.2021.120960

26. Wijayanta AT, Istanto T, Kariya K, Miyara A (2017) Heat transfer enhancement of internal flow by inserting punched delta winglet vortex generators with various attack angles. Exp Therm Fluid Sci 87:141-148. https://doi.org/10.1016/j.expthermflusci. 2017.05.002

27. Chokphoemphun $S$, Pimsarn $M$, Thianpong $C$, Promvonge $P$ (2015) Heat transfer augmentation in a circular tube with winglet vortex generators. Chin J Chem Eng 23:605-614. https://doi. org/10.1016/j.cjche.2014.04.002

28. Liu Hn-I, Li H, He Y-I, Chen Z-t (2018) Heat transfer and flow characteristics in a circular tube fitted with rectangular winglet vortex generators. Int J Heat Mass Transf 126:989-1006. https:// doi.org/10.1016/j.ijheatmasstransfer.2018.05.038

29. Awais M, Bhuiyan AA (2018) Heat transfer enhancement using different types of vortex generators (VGs): a review on experimental and numerical activities. Therm Sci Eng Prog 5:524-545

30. Gallegos RKB, Sharma RN (2017) Flags as vortex generators for heat transfer enhancement: gaps and challenges. Renew Sustain Energy Rev 76:950-962

31. Mahanthesh B, Shashikumar NS, Lorenzini G (2020) Heat transfer enhancement due to nanoparticles, magnetic field, thermal and exponential space-dependent heat source aspects in nanoliquid flow past a stretchable spinning disk. JTherm Anal Calorim. https://doi.org/10.1007/s10973-020-09927-x

32. Rasool G, Shafiq A (2020) Numerical exploration of the features of thermally enhanced chemically reactive radiative PowellEyring nanofluid flow via darcy medium over non-linearly stretching surface affected by a transverse magnetic field and convective boundary conditions. Appl Nanosci. https://doi.org/ 10.1007/s13204-020-01625-2

33. Rasool G, Shafiq A, Baleanu D (2020) Consequences of soretdufour effects, thermal radiation, and binary chemical reaction on darcy forchheimer flow of nanofluids. Symmetry (Basel) 12:1-19. https://doi.org/10.3390/SYM12091421

Publisher's Note Springer Nature remains neutral with regard to jurisdictional claims in published maps and institutional affiliations. 